\title{
MATEO MIMBELA (1663-1736), EL MAESTRO ARAGONÉS QUE ENSEÑÓ FILOSOFÍA Y TEOLOGÍA EN EL NUEVO REINO DE GRANADA
}

\author{
Germán Marquínez Argote \\ Fundación Xavier Zubiri (Madrid)
}

\section{RESUMEN}

Mateo Mimbela contribuyó a la renovación de la tradición escolástica llevada a cabo por los jesuitas en Colombia. En su breve tratado de astronomía muestra un amplio conocimiento de las ideas modernas que contribuyeron a cambiar la vieja idea del mundo.

Palabras clave: Mateo Mimbela, jesuita, astronomía, renovación escolástica, Colombia

\begin{abstract}
The jesuite Mateo Mimbella contributet to renew the scholastic tradition in Colombia. On his short treatise of Astronomy he contains the moderns ideas that changed the old image of the world.
\end{abstract}

Key words: Mateo Mimbela, Jesuit, Astronomy, Scholastic renovation, Colämbia

\section{VIDA Y OBRAS DE MATEO MIMBELA}

\section{Breve noticia biográfica}

Este gran maestro javeriano de finales de siglo XVII y primeras décadas del XVIII, nació en Fraga, antiguo Reino de Aragón, el 20 de septiembre de 1663. El 21 de noviembre del año 1677, cumplidos los catorce, ingresó en el noviciado de la Compañía de Jesús en la ciudad de Tarragona, en la que además estudió humanidades clásicas. Prosiguió estudios de filosofía y teología en Zaragoza. Sin haber concluido estos últimos, en cumplimiento de sus deseos de ir a misiones, el 8 de febrero de 1689 recibió patente del provincial de Aragón P. Diego Jiménez Rojo para viajar al Nuevo Reino de Granada. Pero, habiendo dificultades para embarcarse hacia Las Indias, de paso por Madrid recibió orden de culminar sus estudios teológicos en la entonces célebre Universidad Complutense de Alcalá de Henares. En 1690 pudo, por fin, embarcar, siendo poco antes de emprender el viaje ordenado de sacerdote en Sevilla. Un hecho notable es que dos hermanos suyos, uno franciscano y otro dominico, fueron obispos en Indias, el primero de Guaxaca (México) y el segundo de Santa Cruz de la Sierra y Trujillo (Perú).

Desembarcó Mimbela el 3 de mayo de 1690 en Cartagena de Indias, con un grupo de jesuitas dirigidos por el P. Juan de Segovia. Desde esta ciudad costera ascendió al antiplano andino, llegando a la ciudad de Tunja, donde cumplió el año de la tercera probación, después del cual fue destinado a la vecina ciudad de Santafé, capital del Nuevo Reino, como catedrático 
de la facultad de artes de la Universidad Javeriana. Aquí explicó durante tres cursos cónsecutivos al mismo grupo de alumnos, según la costumbre de la época, lógica, física y metafísica. Del curso de física, dado entre 1692-1693, nos queda el manuscrito de sus lecciones, pulcramente copiado por Juan de Herrera, oyente de las mismas, y cuyo título reza así: Tratado de Física, por el R. P. Mateo Mimbela de la Compañía de Jesús, dignísimo profesor de la Cátedra de Filosofía de esta Academia Javeriana de la ciudad de Santafé. En el día vigésimo del mes de octubre, en el año 1693 desde el nacimiento del Señor. [Copiado] por el oyente, Juan de Herrera» ${ }^{1}$. En el «Prólogo a los oyentes» hace alusión al anterior curso de lógica o dialéctica, leído entre 1691-1692, calificándola de «espinoso matorral» (sentes spineta), lo cual parece indicar que no le quedaron gustando demasiado los temas lógicos. En cambio, al empezar el segundo curso pondera Mimbela a sus alumnos de segundo de artes las excelencias de la física, comparándola con unos «amenos jardines» (amena viridaria):

«INGENIOSOS DISCÍPULOS. Nos disponemos a enseñar el tema de la naturaleza corpórea, parte muy importante de la filosofía, evitando el espinoso matorral de la Dialéctica [Lógica]; el año pasado finalizamos ese largo trabajo, bastante arduo, llevándolo a feliz término con la ayuda de vuestras mentes y espíritus eminentes. Ahora, el orden que ha de guardarse religiosamente nos invita a los amenos jardines de la Fisiología [Física]. Y no es necesario para poner en evidencia el interés del tema, recurrir a ficciones retóricas o adornarse con palabras, puesto que las cosas que se refieren a la contemplación de la naturaleza anticipadamente manifiestan su valor por sí mismas. ¿Habrá algo más grato a la inteligencia humana? ¿Algo más digno de conocer que los repliegues más recónditos de la naturaleza, lo más secreto de sus causas y, todavía más, de tomar con las manos la misma máquina celeste?

«Prosiguiendo el orden que religiosamente ha de guardarse», entre 1663-1664 explicó la metafísica, correspondiente al tercer curso de artes, al mismo grupo de estudiantes con que se había iniciado como maestro tres años antes. Refiriéndose a su magisterio filosófico, afirma el P. Cassani que Mimbela «leyó [las materias de los tres cursos] con aplauso general, siendo estimados sus papeles por metafísicos, por sólidos, por claros y por formales ${ }^{2}$.

Una vez terminado en 1695 el trienio de artes como profesor, Mimbela recibió con satisfacción la orden de viajar a los territorios todavía selváticos del sur del río Meta en los Llanos Orientales con el P. Alfonso Neira, «lenguaraz, hábil y experimentado en misiones», según calificativos que le da Cassani. Aquí se sintió feliz conviviendo con los indígenas en medio de una naturaleza selvática durante casi tres años, al cabo de los cuales regresó a Santafé, donde presentó el informe requerido sobre el gentío descubierto en el Ayrico, sobre las posibilidades de implantar la fe y reducir a los gentiles y también sobre la calidad de las tierras y las posibles vías de acceso hacia el Orinoco. Pero cuando más ilusionado estaba con volver a misiones, contrariando sus más profundos sentimientos y vivos deseos, fue nombrado de nuevo catedrático de la Javeriana, esta vez en la facultad de teología.

Fruto de las lecciones dadas durante el primer curso teológico de 1698-1699 es el manuscrito, titulado: Tratado de la esencia y atributos de Dios, por el R. P. Mateo de Mimbela, dignísimo moderador de la cátedra de Vísperas ${ }^{3}$, al parecer redactado de su puño y letra. En

1 Physices tractatus, P[er] R. P. Matheum Mimbela Societatis Iesu dignissimum Philosophiae Cathedrae Praeceptorem huius Xaverianae Accademiae Civitatis SanctaFidensis. Die vigesima mensis Octobris, anno a Nativitate Domini 1693. Joanne de Herrera, Auditore

2 CASSANI, Joseph. «Vida del Padre Mateo Mimbela», en Historia de la Provincia de la Compañía de Jesús del Nuevo Reino de Granada, p. 607.

3 Tractatus de essentia et atributis Dei. Per R. P. Matheum de Mimbela vespertinae cathedrae moderatorem dignissimum. Initium dedi die 19 mensis Octobris. Anno 1699. Al parecer, está escrito de mano del propio Mimbela, puesto que dice en primera persona: Initium dedi..., «di comienzo» y Finem aposui..., «puse fin» al manuscrito. 
el Prólogo al mismo hace Mimbela dos interesantes confesiones personales: la primera, que «habiendo interrumpido el pensum de las controversias escolásticas durante tres años [los pasados en Los Llanos], soy de nuevo obligado a comenzar (iterum cogor instaurare); y, aunque conozco plenamente cómo es de exigua la capacidad de mi ingenio, el mandato de aquellos que ejercen el mando, me ofrece no pequeña esperanza de que he de cumplir debidamente con la tarea». El hecho de que aceptara la cátedra vespertina de teología como una obligación perentoria, confirma que después de la experiencia de Los Llanos le quedó gustando más el monte que ciudad y la academia, y que su vocación más profunda, que ya nunca ejercería, fue la de misionero.

En la segunda confesión se refiere a la angustiosa falta de tiempo que padece (me cogunt temporis angustiae). No le queda tiempo para preparar, como quisiera, los cursos que le habían asignados, de tal manera que, según dice, «procuraré suplir con trabajo ímprobo (improbo labore), lo que la falta del tiempo me ha negado». Y es que desde su retorno a Santafé hasta el final de su vida le tocó desempeñar todos los cargos administrativos imaginables: fue sucesivamente maestro de novicios y rector del colegio de Tunja (1703-1711), secretario, viceprovincial, provincial (1713-1716), prefecto de estudios, procurador general de la provincia en Madrid y Roma (1721-1723), tres veces rector de la propia Universidad Javeriana, etc. Más un»cursus honorum», todos estos cargos representaban pesadas cargas, exigiéndole frecuentes ausencias de Santafé y largos viajes a lomo de bestia. En cierta ocasión, al aproximarse a Tunja se le encabritó el caballo y dio en tierra con sus huesos, resultando tan quebrantados los de una pierna, que tardaron más de un año en soldar, quedando cojo y doliente de por vida el dueño de los mismos. Con todos estos trabajos y quebrantos no es difícil imaginar por qué sólo se conservan dos manuscritos de Mimbela, correspondientes ambos a los primeros años de profesorado; en adelante no le quedó tiempo para sentarse a escribir, aunque durante sus estancias en Santafé, siempre que podía, dictó lecciones de teología con responsabilidad y éxito ante los alumnos. Refiriéndose al cumplimiento oral de sus deberes escolásticos, el P. Cassani destaca el talante obediente y responsable con que los desempeñó Mimbela:

«Bajó el cuello, recibió el yugo, entró en las cátedras, y las siguió hasta la de prima, regentando con tanto cuidado y estudio, que ningún año repitió materia, trabajando de nuevo cada año la que había de dictar. Sólo un año repitió una materia dictada dos años antes, porque había logrado tanto aplauso, que deseosos de tenerla todos, le pidieron con instancia su repetición» ${ }^{4}$.

Pese a no haber podido realizar su vocación misionera, se debe a Mimbela una importante decisión para las misiones de Los LLanos y para la cultura neogranadina. Corriendo el año 1715, estando en Tame en visita de provincial prometió a los indios betones mandarles un padre, de manera que a su regreso a Santafé, cumpliendo su promesa, les envió al valenciano Joseph Gumilla, que resultó no sólo un buen misionero, sino un excelente explorador, etnólogo y estudioso de la fauna y la flora de la Orinoquía, aspectos que dio a conocer en su famosa obra El Orinoco ilustrado5.

4 CASSANI, o. c., pp. 605-618. A propósito de Mimbela, escribe el P. DEL REY: «Dos etapas, claramente diferenciadas, observamos en la biografía de este jesuita: la académica (1691-1702) y la del cursus honorum (17021735)», en Bio-bibliografía de los jesuitas en la Venezuela Colonial, 2a. edic., p. 403.

5 El título de la obra da noticia muy completa del autor y del contenido de la misma: El Orinoco ilustrado. Historia Natural, Civil y Geographica, de este Gran Río, y de sus caudalosas vertientes: Govierno, usos, y costumbres de los indios sus habitantes, con nuevas y útiles noticias de Animales, Arboles, Aceytes, Resinas, Yervas, y Raíces medicinales: Y sobre todo se hallarán conversiones muy singulares a nuestra Santa Fe, y casos de mucha edificación. Escrita por el P. Joseph Gumilla, de la Compañia de Jesús, Missionero, y Superior de las Missiones del Orinoco, Meta, y Casanare, Calificador, y Consultor del Santo Tribunal de la Inquisición de Cartagena de Indias, y Examinador Synodal del mismo Obispado, Provincial que fue de su Provincia del Nuevo Reyno de Granada, y actual Procurador de entreambas Curias, por sus dichas Missiones y Provincia. Madrid, Por Manuel Fernández, 1742. 
Después de 73 años de larga y fecunda vida, dedicada a la administración de los asuntos de la comunidad y siempre que podía a la academia, Mimbela, «rodeado de la estimación de todos, falleció el 22 de abril de 1736, cuando ejercía su tercer rectorado de la Universidad Javeriana» ${ }^{6}$.

\section{LAS OBRAS MANUSCRITAS DE MMMBEA}

La obra escrita de Mimbela, como ha quedado dicho, se reduce a los dos manuscritos anteriormente citados: uno de filosofía y otro de teología, ambos de finales del siglo XVII; por ello, para efectos de la historia de la filosofía carece de sentido contar a Mimbela (menos aún a Ripalda), entre los autores del siglo XVIII, como lo hace el P. Pacheco ${ }^{7}$. Señalemos algunas de las características generales de ambos tratados.

El Physices Tractatus se conserva en los archivos de la Biblioteca Nacional con el n. 149. Encuadernado en pergamino, consta de 148 folios $(21 \times 15 \mathrm{~cm}$.), que contienen los temas generales de la física; a continuación del Index, sigue a modo de apéndice una serie de páginas sin titulación, numeradas de 1 a 12, que corresponden al clásico tratado De Caelo, que se explicaba como complemento de la física. En el último párrafo, a modo de colofón, se califica este apéndice como Brevis tractatio de caelo et astris, título que hacemos nuestro. La grafía de todo el manuscrito es esmerada, lo que indica que el oyente o alumno copió primero unos apuntes de clase, que posteriormente transcribió con más sosiego y esmero, tanto que la escritura manual se acerca mucho en perfección a la imprenta. Los dibujos de la portada y las letras capitales de las distintas unidades así lo confirman. El copista pudo ser el mismo oyente Juan de Herrera, u otra persona experta en caligrafía. Es posible que dicho Juan de Herrera fuera el famoso compositor de música sinfónica, que por estos años estudió en la Academia Javeriana.

En cuanto a su estructura formal, no se trata de unos simples «comentarios» a la Física del Estagirita a la vieja usanza escolástica; sino, como reza el título, la de un verdadero «tractatus» vertebrado, dividido en libros, disputaciones, secciones, subsecciones, apéndices y números, siguiendo la nueva tradición instaurada por el Doctor Eximio, Francisco Suárez, en las Disputationes metaphysicae. En cuanto al orden de los temas sigue el de la física aristotélica, como puede apreciarse en el «Índice de todos los temas contenidos en este tratado de los ocho libros de los físicos», que presentamos en forma abreviada a continuación:

Presentación a los estudiantes (fol. 1).

Breve explicación de las cuestiones introductorias de física $(f .2 v)$

Libro $1^{\circ}$ de los Físicos: Sobre los principios intrínsecos del ser natural (f. $2 v$.)

Disp. $1^{a}$ : Sobre los principios del ser natural en común $(f .2 v)$

Disp. $2^{a}$ : Sobre la existencia de la materia prima y su esencia (f.6)

Disp. $3^{a}$ : Se explican otros predicados y propiedades de la materia prima $(f .16)$

Disp. $4^{a}$ : Sobre la forma substancial (f. 27v)

Disp. 5a: Sobre la unión entre la materia y la forma (f. 35)

Disp. $6^{a}$ : Sobre el todo o compuesto substancial (f. 40)

Libro $2^{\circ}$ de los Físicos: Sobre la naturaleza, el arte y las causas (f. $\left.43 \mathrm{v}\right)$.

Disp. $1^{a}$ : Sobre la naturaleza y el arte (43v)

Disp. $2^{a}:$ Sobre las causas en común $(f .47 v)$

6 Sobre Mimbela hay amplia información en PACHECO, J. M. Los Jesuitas en Colombia, t. III, pp. cap. 3, pp.149-172; y en «La Universidad Javeriana...», pp. 148-151;

7 J. M. PACHECO clasifica a Ripalda y Mimbela como catedráticos del siglo XVIII. Aunque es verdad que murieron ambos en 1707 y 1736 respectivamente, no obstante la obra publicada del primero y la manuscrita del segundo pertenecen a cursos dados en la Universidad Javeriana en las últimas décadas del siglo XVII. 


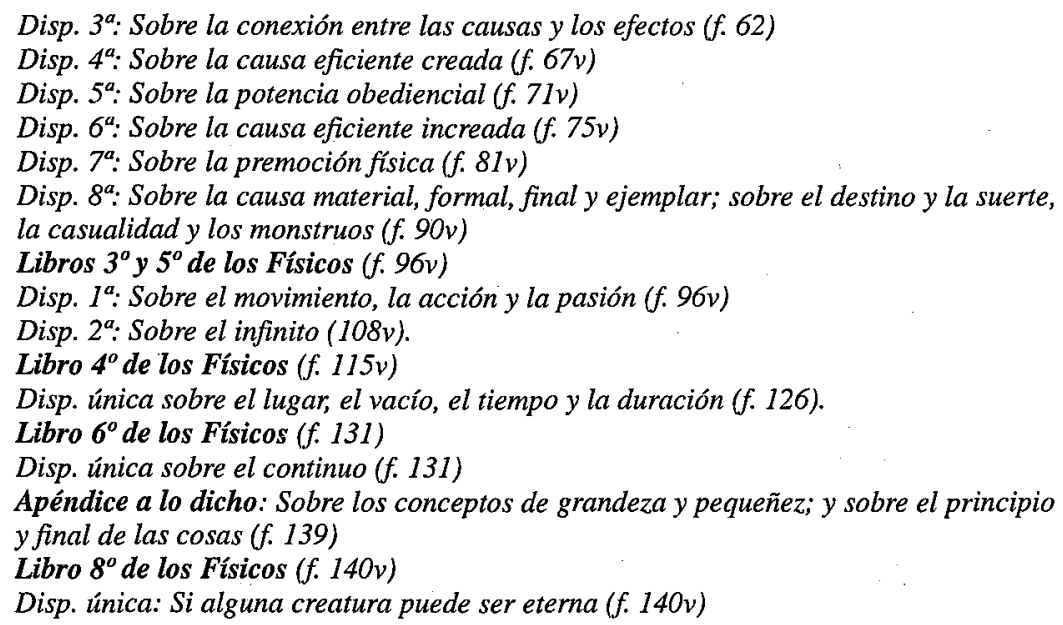

Como puede verse, Mimbela agrupa los libros tercero y quinto y no comenta el séptimo. Los contenidos de todos ellos son en su mayor parte los tradicionales de los maestros de la segunda escolástica, siguiendo especialmente las enseñanzas de Francisco Suárez, cabeza de la escuela jesuítica. No obstante, llaman la atención algunos aspectos del tratado, que voy a destacar.

Juan David García Bacca, reconocido filósofo y traductor de algunos textos de autores coloniales de Venezuela y Colombia, dice que Mimbela en el Tratado de física llega a afirmar dos tesis que, a la luz de la física cuántica, le parecen interesantes: la primera, que «la ubicuidad no es un atributo de Dios y sólo de él. Solamente pertenece a Dios la ubicuidad necesaria: tiene que estar en todas las partes del Universo, no tanto por necesidad suya, cuanto por necesidad del universo. Mas un cuerpo puede estar en muchos y aún en todos los lugares, mas no necesariamente». Segunda tesis, que «la extensión no es una propiedad esencial y fija del cuerpo. Extensión es efecto de la presencia, y como un cuerpo puede tener diversas presencias, su extensión puede cambiar, sin que él mismo cambie en su constitución» ${ }^{8}$.

Por su parte, Miguel Ángel González Castañón, traductor del primer libro del Tratado de física, escribe: «El Padre Mateo Mimbela es un maestro de filosofía con personalidad. Expone con autoridad, contradiciendo incluso en un par de ocasiones al cabeza de la escuela jesuítica, Francisco Suárez. No tiene empacho en discutir algunos puntos con el mismo Aristóteles. Eso sí, se declara siempre de acuerdo con Santo Tomás, aunque discrepando de las interpretaciones de los tomistas dominicos [...] La mayor audacia doctrinal de Mimbela tal vez sea su oposición a Aristóteles, Tomás de Aquino y Suárez, su cabeza de escuela, sosteniendo la opinión de que «lo más probable es que la materia celeste no sea distinta de la sublunar» ${ }^{9}$. La importancia de esta tesis, la veremos en el próximo capítulo, cuando estudiemos el pequeño tratado sobre el cielo y los astros.

Por mi parte, quiero destacar otros dos aspectos. El primero es el tema de los «modos substanciales», en el que Mimbela sigue la doctrina de Súarez. La unión entre la materia prima y

8 GARCÍA BACCA, Juan David. Antología del pensamiento filosófico en Colombia(De 1647 a 1761). Bogotá, Imprenta Nacionañ, 1955, p. 60.

9 GONZÁLEZ CASTAÑÓN, Miguel Ángel. Transcripción, traducción y estudio crítico del «Tratado de física», libro I, del R. P. Mateo Mimbela, S. J., de la Academia Javeriana, Santafé de Bogotá 1693. Tesis inédita, defendida por el autor para optar al magister en filosofía latinoamericana. Bogotá, Universidad Santo Tomás, 1997, pp. 19,50 . 
la forma consiste formalmente en un modo substancial, realidad distinta de los extremos unidos y de las acciones necesarias para la producción de dicha unión. En este punto, Mimbela entra en discusión con «un ingenioso moderno (ingeniosum recentiorem) que defiende en solitario una opinión singular (singularis sententia), a saber, que toda unión, desde el punto de vista activo, consiste en el modo en que se efectúa dicha acción; y desde un punto de vista formal y terminal, en los extremos mismos cuanto en ellos finaliza a la vez tal acción ${ }^{10}$. Este ingenioso moderno no era otro que Juan Martínez de Ripalda, con quien el aragonés coincidió en las aulas de la Universidad Javeriana como catedrático de artes, cuando el navarro era ya un profesor consagrado de la facultad de teología. Ripalda, siempre original, negaba efectivamente la necesidad de los supuestos modos substanciales que, a modo de «pegamento" metafísico, unían los extremos. La materia prima y la forma se unen por sí mismas sin necesidad de un supuesto no probado «tertium quid». Mimbela replicaba a su compañero Ripalda que, negada la existencia de dichos modos suarecianos, difícilmente se podría explicar la unión de cuerpo-alma en el hombre, o la unión hipostática de la naturaleza humana de Cristo con la persona del Verbo en teología. Era éste el discutido problema de la subsistencia o del último constitutivo formal de la persona, que Cayetano y Suárez interpretaban como un modo substancial negativo o positivo respectivamente ${ }^{11}$.

Un segundo aspecto se refiere a la célebre discusión acerca del concurso divino a las acciones libres de las creaturas, cuando éstas deciden realizar actos moralmente malos. En tal caso, afirma Mimbela, «para los efectos libres moralmente malos no se aplica la omnipotencia de Dios mediante un decreto que quiera tales efectos, sino por un decreto que quiere que existan los requisitos [para la acción libre] y que al mismo tiempo quiere eficazmente que no haya impedimento insalvable para la voluntad humana». $Y$ añade, seguidamente, que esta conclusión «ha sido sustentada por los Padres Raimundo Rice, Hurtado y por el Padre Elías Muniessa últimamente, entre otros ingeniosos Reverendos; también fue del agrado de un profesor reciente de filosofía y de teología, muy conocido en esta Academia Javeriana». Este profesor era el mismo Ripalda, quien negaba tales decretos divinos predeterminantes, supuestos por Báñez y la escuela tomista, por ser incompatibles con la libertad humana, admitiendo en cambio una moción divina previa, pero indiferente o respetuosa del acto libre ${ }^{12}$.

El segundo manuscrito, que de Mimbela conservamos, es el titulado Tractatus de essentia et atributis Dei. Consta de 115 folios ( $21 \times 13$ ), que al parecer fueron escritos de su puño y letra. Contiene las lecciones dadas en la facultad de teología durante el curso 1698-1699, dado a la vuelta de la misión de los Llanos ${ }^{13}$. Aunque, al final de esta obra, reproducimos facsimilarmente el «Índice de las disputaciones, secciones, subsecciones y cuestiúnculas, que se contienen en este tratado», damos a continuación una síntesis de los temas generales contenidos en el mismo:

10 MIMBELA, M. Physices tractatus, lib. I, disp. 5, concl. 2, n. 264. En este lugar, Mimbela resume fielmente el pensamiento de Ripalda, quien escribe: «Esta es nuestra conclusión: La unión no es un modo realmente sobreañadido (modus realiter superadditus), que media entre la materia y la forma (inter materiam et formam medians). Por tanto, la unión desde el punto de vista ejecutivo (per modum exercitii) consiste en la acción; desde el punto de vista terminal o formal (terminative et formaliter) consiste en las mismas partes, en cuanto conjuntamente son término de tal acción (ut simul terminant talem actionem)», MARTÍNEZ DE RIPALDA, J. De usu et abusu doctrinae Divi Thomae. Pars I, opusc. 7, lec. 2, n. 333.

11 ALCORTA, J. Ignacio. La teoría de los modos en Suárez. Madrid, CSIC, 1949; y FORMENT, Euvaldo. Persona y modo substancial. Barcelona, Publ. Universitarias, s. f.

12 MIMBELA, M. Physices tractatus, lib. 3, disp. 6, concl. 3, n. 598, p. 79.

13 Al final del manuscrito se lee: «Finem apposui die 23 Julii anno Domini $1699 »$, lo cual está en contradicción con la fecha de la portada: «Initium dedi die 19 Octobris Anno 1699»; es evidente que no pudo poner fin al curso y al manuscrito antes de haberlos empezado. Consideramos, por tanto, que el error está en la portada del manuscrito, que debiera decir: «Anno 1698». En conclusión, dichas lecciones las leyó Mimbela en el curso dado en la facultad de teología entre el 19 de octubre de 1698 y 23 de julio de 1699. 
Disp. $1^{a}$ Sobre la cognoscibilidad de Dios (f.2)

Disp. $2^{a}$ Sobre la existencia de Dios (f. 9)

Disp. $3^{a}$ Sobre el constitutivo metafisico de la esencia de Dios (f.18)

Disp. $4^{a}$ Sobre la infinidad y perfección de Dios $(f .31)$

Disp. $5^{a}$ Sobre la vida de Dios (f. 43)

Disp. $6^{\alpha}$ Sobre la subsistencia de Dios (f. 53)

Disp. $7^{a}$ Sobre los atributos de Dios en común (f. 63)

Disp. $8^{a}$ Sobre la omnipotencia de Dios en particular $(f .81)$.

Disp. $9^{a}$ Sobre la justicia de Dios (f. 88)

Disp. $10^{a}$ Sobre la eternidad de Dios $(f .100)$

Disp. $11^{a}$ Sobre la inmutabilidad e inmortalidad de Dios (f. 107)

Disp. 12 ${ }^{a}$ Sobre la incomprensibilidad de Dios (fol. 112-117).

Sería interesante hacer un estudio detallado de este tratado que, por ser de teología «especulativa», que así lo llamaban los escolásticos, coincide en gran parte de sus explicaciones con lo que después tituló Leibniz «teodicea» y que posteriormente se conoció como «teología natural o racional», por estudiar a Dios con la sola luz natural de la razón. Pero nos apartaríamos del tema central de esta investigación si nos extendiéramos en estas cuestiones teológicas. Quiero, no obstante, comentar brevemente un punto, que para mí fue toda una sorpresa, y es que Mimbela defiende que se puede demostrar la existencia de Dios no sólo con las clásicas pruebas a posteriori (movimiento, causalidad eficiente y contingencia), sino también por las llamadas pruebas a priori, que partiendo del análisis de los conceptos de «sumo bien» o «ser perfectísimo», tratan de demostrar la existencia de Dios de forma analítica y necesaria, como correlato real de su propia definición.

Es sabido que la prueba a priori, de origen platónico-agustiniano, la planteó San Anselmo en el Proslogion cap. 2; que la refutó Santo Tomás en la Summa Theologiae I, q. 2, a. 2, ad 2; que la restauró Descartes en las Meditationes de prima philosophia III y la hizo suya Leibniz en la Monadologie n. 45; que Kant la rechazó bajo el nombre de «argumento ontológico». Esta reviviscencia del argumento ontológico no fue fortuita, si se tiene en cuenta que el horizonte último de comprensión en la modernidad lo constituyen las ideas «claras y distintas», a partir de las cuales Descartes pretende alcanzar la realidad no sólo del sujeto que las piensa, sino también la realidad de Dios que garantiza su verdad, y la realidad del mundo corporal pensado según el modelo matemático de extensión con cierta cantidad constante de movimiento. La filosofía moderna está centrada en las ideas objetivas, a partir de las cuales pretende ganar la realidad (realismo mediato o «ideísmo» como lo llama Zubiri), o termina finalmente quedándose en el mundo inmanente de las representaciones como último reducto de la realidad (diversas formas de idealismo $)^{14}$.

Dentro de este horizonte moderno, no es extraño que se reivindique el argumento ontológico como la forma más adecuada de probar la existencia de Dios. A partir de la esencia divina, definida como «conjunto de todas las perfecciones posibles», se demuestra la existencia de dicho ser perfectísimo, es decir, de Dios, puesto que por definición al ser perfectísimo no puede faltarle la perfección de la existencia. Este argumento no sólo lo utilizan grandes racionalistas como Descartes y Leibniz, sino muchos escolásticos modernizantes, algunos incluso con anterioridad a aquellos. Ramón Ceñal en un documentado trabajo estudia a once reconocidos escolásticos, en su mayor parte jesuitas, partidarios de dicho argumento, frente a nueve que se

14 En Sendas perdidas M. Heidegger caracteriza el horizonte de la modernidad como la «época de la imagen del mundo» o del mundo reducido a imagen por una subjetividad constituyente del mundo de los objetos. Cf. mi obra Los principios de la intelección humana del maestro javeriano Juan Martínez de Ripalda, Santafé de Bogotá, CEJA, 1988, I pat., cap. 3. 
muestran críticos del mismo ${ }^{15}$. Son partidarios del argumento ontológico: Antonio PÉREZ, S.J. (1599-1649); Francisco GONZÁLEZ DE SANTA CRUZ, S. J. (1591-1661); Matías BORRUL, S.J. (1615-1689); Pedro GODOY, O. P. (m. 1677); Tomás MUNIESSA. S. J. (16271696); Martín DE ESPARZA Y ARTIEDA, S. J. (1606-1689); Juan Bautista TOLOMEY, S. J. (1653-1726); Domingo VIVA, S. J. (1684-1726); Juan Bautista GOMAZ, S. J. (1650-1708); Juan de ULLOA, S. J. (1639-1721); Juan Vicente TOSCA, Orat. (1651-1723). Los contrarios al argumento son: Rodrigo ARRIAGA, S. J. (1592-1667); Sebastián IZQUIERDO, S. J. (16071681); Antonio DE QUIRÓS, S. J. (1613-1668); Silvestre MAURO, S. J. (1619-1687); José SÁENZ DE AGUIRRE, O. S. B. (1630-1699); Cristóbal HAUNOLD, S. J. (1610-1689); Francisco POLANCO, O. Min. (1657-1720). Si se tiene en cuenta la anterior lista de partidarios y de críticos, no parece justa, al menos referida a los jesuitas españoles del siglo XVII, la siguiente apreciación de Leibniz: «Les scholastiques, sans excepter même leur Docteur Angelique, ont méprise cet argument, et l'ont fait passer pour un paralogisme; en quoy ils ont eu un grand tort, et $M$. des Cartes qui avoit étudié longtemps la philosophie scholastique au Collège de la Fleche, a eu grande raison de le rétablim (Nouveau Essais, IV, c. 10, n. 7, Edic. Gerhard, t. V, p. 418). Pues bien, en este punto Mateo Mimbela sigue a sus correligionarios Antonio Pérez y Tomás Muniessa, fervorosos defensores del mismo, planteando dicho argumento ontológico hasta en tres formas distintas:

«Sea, pues, la segunda Conclusión: la existencia de Dios es demostrable a priori. [...] Se demuestra:

1. El ser que contiene toda la bondad y perfección no es contingente ni es imposible: luego es posible y necesario; tal es Dios: luego Dios existe. [Se prueba que no es contingente]: un ente que contenga toda perfección tiene que existir, y no puede ser contingente porque podría no tener toda la perfección, lo que va contra los términos mismos. [Se prueba que no es imposible]: una perfección no es de suyo contradictoria con otra, ya que lo contradictorio de una perfección lo es solamente la imperfección.

2. A esto mismo viene a parar la razón que trae el P. Antonio Pérez, y de él la toma el $P$. Muniessa: No es ninguna clase de bien ser quimera; es asi que lo que carece de todo defecto [es decir, Dios] es un bien: luego [Dios] no es quimera. [...] Carecer de todo defecto no sólo es un bien, sino que es el sumo bien: luego el ser carente de todo defecto existe».

3. Posible es lo que, supuesto, no trae consigò inconveniente alguno; es así que de suponer un ser que carezca de toda imperfección [es decir, Dios] no se sigue inconveniente alguno: luego [Dios] es posible y, si es posible, existe. [...] Implica contradicción que de la suposición de todo bien y perfección se siga mal alguno o imperfección [inexistencia]. Omito otras demostraciones que podría traer, pero que no hacen falta dado los fines que intentamos ${ }^{16}$.

Antes de poner punto final a este capítulo, baste recordar que Guillermo Leibniz en su $\mathrm{Mo}$ nadologie (1714) formula la prueba de manera casi coincidente con la tercera de las formulaciones de Mimbela: «Dieu seul, ou l'être nécessaire, à le privilège qu'il faut qu'il existe, s'il est possible. Et comme rien ne peut empêcher la possibilité de ce qui n'enferme aucunes bornes, aucune negation et par conséquent aucune contradiction; cela seul suffit pour connaître l'existance de Dieu a priori» (Monadologie, n. 45, edic. Erdmann).

15 CEÑAL, Ramón. «El argumento ontológico de la existencia de Dios en la escolástica de los siglos XVI y XVII», en Homenaje a Zubiri. Madrid, Moneda y Crédito, 1979, tom. II, pp. 245-325.

16 En la Biblioteca de la UJ se halan las obras de PÉREZ, Antonio, S. J. Quinque tractatus in primam partem Sancti Thomae. Romae, 1656 y MUNIESSA, Tomás, S. J. Disputationes scholasticae de essentia et atributis Dei. Barcinone, 1687, autores citados y seguidos por Mimbela. 


\section{ENTRE LA TRADICIÓN Y LA MODERNIDAD}

\section{Un prejuicio histórico}

Con motivo de la muerte de don José Celestino Mutis, ocurrida el 11 de septiembre de 1808, su discípulo Francisco José de Caldas dedicaba a su admirado y llorado maestro una bella y emocionada laude, en la que, entre otras cosas, afirmaba:

«En 1760 desembarcó [Mutis] en Cartagena de Indias, año para siempre memorable en los fastos de nuestros conocimientos [...] En aquella época se empezó a oír en el [Nuevo] Reino que la Tierra giraba sobre su eje y al rededor del Sol, y que se debía poner en el número de los planetas. ¡Cuántos disgustos le costó persuadirnos de esta verdad capital en la astronomía» ${ }^{17}$.

Se refiere el sabio Caldas, en primer lugar, a la importancia que Mutis tuvo para la cultura neogranadina; ciertamente, su venida fue un hecho de primer orden. En segundo lugar afirma que sólo con la llegada de Mutis «se empezó a oír» hablar en el Nuevo Reino de que el Sol ocupaba el centro del universo y que la Tierra giraba en torno suyo. Hoy esta afirmación es indefendible, pese a que se ha convertido en tópico histórico, a fuerza de repetirla. Hay documentos que confirman que con anterioridad a la llegada de Mutis se había expuesto la teoría heliocéntrica en los claustros universitarios del Nuevo Reino. De manera que, si esto es así, no fue Mutis el primero en dar a conocer las ideas de Copérnico y Galileo, aunque hay que abonarle que la defensa que de ellas hizo fue definitiva para terminar de aclimatar entre nosotros la nueva «imago mundi». Ciertamente Mutis representa un verdadero salto cualitativo, pero no es el kilómetro cero de la modernidad en la historia cultural colombiana.

En cuanto a los «disgustos», a los que hace referencia el sabio Caldas, es sabido que fueron motivados por la agria querella que Mutis sostuvo con los padres Dominicos, a raíz de la convocatoria a unas conclusiones públicas, en las que los representantes de la Universidad Tomista rechazaban (todavía en 1774) el copernicanismo «por ser intolerable para los católicos e indefendible como tesis, y más intolerable aún teniendo en cuenta la prohibición de la sagrạda Inquisición». Pretendían con dicho acto público responder en forma contundente a Mutis, quien, en conclusiones públicas celebradas el año anterior de 1773 en el Colegio del Rosario, había defendido en forma brillante ante el virrey Guirior el sistema copernicano. Hay que decir que dicha confrontación se planteó solamente entre los representantes del Colegio de Santo Tomás y José Celestino Mutis. Ni el Colegio del Rosario, ni el de San Bartolomé tuvieron arte ni parte en la misma y en los consiguientes reproches y mutuos disgustos. Tan es así, que con anterioridad a 1767 Mutis había sido invitado a exponer sus ideas en el Colegio Máximo de la Compañía, en el que fue oído con el respeto que merecía su autoridad científica ${ }^{18}$.

No pretendo en este cápítulo hacer historia de este triste episodio. Tampoco voy a tratar de rebajar los méritos que universalmente le son reconocidos al sabio Mutis como introductor de las ciencias útiles en el Nuevo Reino y como aclimatador en nuestro medio de la mentalidad moderna, que implicaba una nueva imagen del universo. Sobre estos temas se han escrito miles de páginas. Este capítulo se centra en un tema de nuestra historia cultural poco conocido, a saber: la recepción de las ideas de Copérnico, Brahe y Galileo en el Breve tratado de los cielos y los astros de Mateo Mimbela, texto leído en la Universidad Javeriana en la temprana

17 CALDAS, Francisco José. «Artículo necrológico», escrito con ocasión de la Muerte de J. C. Mutis, en Obras completas. Bogotá, Universidad Nacional de Colombia, 1966, pp. 20-21.

18 El pensamiento científico y filosófico de José Celestino Mutis. Recop. y selec. de textos por Guillermo Hernández de Alba. Bogotá, Fondo Cultural Cafetero, 1982. 
fecha de 1693. Este texto invalida la afirmación de que sólo con la venida de Mutis en 1760 «se empezaron a oír» en el Nuevo Reino de las nuevas teorías cosmológicas. De este trillado tópico y falso «pre-juicio» histórico, sostenido más por la fuerza de la repetición que por la verdad de los hechos, se ha alimentado la historiografía colombiana. En el siglo pasado, por ejemplo, lo reproduce en su Historia de la literatura en la Nueva Granada José María Vergara y Vergara, quien comentando el Tratado de astronomía (1696) escrito por el licenciado Sánchez de Cozar, escribe:

«Notable, notabilísima es la erudición del autor en conocimientos astronómicos, en una época en que apenas empezaban a vulgarizarse en Europa las grandes verdades descubiertas por Galileo y Kepler, Tycho Brahe, Bacon, Descartes y Newton, que florecieron en el mismo siglo XVII. En la colonia no podían haber penetrado aquellas [grandes verdades]» ${ }^{19}$.

Ciertamente, en el tratado de astronomía del licenciado Sánchez no hay huella alguna de los modernos matemáticos y astrónomos, pero de ello no se sigue, como pretende Vergara, que durante el siglo XVII «no podían haber penetrado» por otros conductos las nuevas teorías astronómicas en el Nuevo Reino.

Ya en nuestros días, Regino Martínez-Chavanz califica el tratado de Mimbela como perteneciente «a la más pura tradición hipostática y enteléquica» ${ }^{20}$. A su vez la investigadora argentina Celina Lertora Mendoza se sorprende de que en los cursos de física de Urbina, Mimbela, Ferrer, Folch y Hernández, por ella estudiados, «no haya ninguna referencia significativa a todo el trabajo científico de la modernidad». Aunque reconoce que Copérnico fue citado por primera vez en 1693 por Mimbela, su obra le merece el siguiente juicio de valor negativo: «Sucede que el profesor colonial juzga a los filósofos y científicos de su tiempo (muy de paso y con poco conocimiento) desde las teorías escolásticas que profesa y defiende» ${ }^{21}$. Si se analiza medianamente el texto de Mimbela, es evidente que el anterior juicio de valor no hace justicia a la historia.

Los anteriores juicios obedecen a un arraigado prejuicio histórico, el de la supuesta «tibetanización» de España en el siglo XVII, que José Ortega y Gasset puso de moda. En el curso 1948-1949 dado en Madrid y publicado posteriormente con el título Una interpretación de la historia universal, Ortega describía así dicho fenómeno:

«España que en el siglo XVI está abierta a todos los vientos, y hasta corporalmente se halla por todo el planeta, por casi todo el mundo, en la primera mitad del siglo XVII comienza a ensimismarse, de modo muy extraño, durante el reinado de Felipe IV [16211665]. Este hecho es, en parte, perfectamente normal, porque, aunque no lo hayan advertido los historiadores, todas las naciones de Europa, por razones constitutivas y fisiológicas en la evolución de un pueblo, hacen entonces cosa parecida [...] España no se contenta con quedar absorta en si misma [...], sino que esta absorción se exagera hasta convertirse en hermetización; España se hizo, por vez primera hermética hacia el resto del mundo, incluso de su propio mundo hispánico. Es lo que yo llamo <tibetanización>

19 Tratado de astronomía y de la reformación del tiempo, del presbitero Antonio Sánchez de Cozar Guanienta, párroco de la ciudad de Vélez, donde al parecer lo escribió en 1696. Biblioteca Nacional, man. n. 245. Presume su autor de haber hallado la clave del computo de la edad del mundo, para con ella establecer con exactitud el año del nacimiento de Cristo y reformar así el calendario cristiano. La parte introductoria de dicho manuscrito fue publicada en Cuadernos de Filosofia Latinoamericana 54 -55 (1993) pp. 155-167.

20 MARTÍNEZ-CHAVANS, Regino. «La Física en Colombia..Sü historia.y su filosofía», en Historia social de la ciencia en Colombia. Bogotá, Colciencias, 1993, t. III, p. 70.

21 LERTORA MENDOZA,Celina. Fuentes para el estudio de las ciencias exactas en Colombia. Bogotá, Academia Colombiana de Ciencias, 1975, p. 21. 
de España, que entonces acontece. El sentido plenario de este término sólo se da en el Tibet, pero el caso es que dentro del occidente ningún otro pueblo ha demostrado como el pueblo español esa tendencia a retraerse y absorberse en sí mismo»22.

No voy a negar que tal fenómeno se produjera, ni tampoco voy a exculparlo del carácter negativo que tuvo para el avance de las ciencias en el mundo hispano. Pero a la luz de la historia se puede demostrar que tal fenómeno no fue tan absoluto como pueden dar pie a pensar los términos «tibetanización» y «hermetización», empleados por nuestro brillante filósofo. Ciertamente, el ensimismamiento de España fue un fenómeno real, pero un tanto relativo. Haciendo las convenientes matizaciones, el historiador José María López Piñero muestra cómo el proceso de la ciencia española en el siglo XVII atravesó por tres períodos: en el primero, que corresponde a las cuatro primeras décadas del siglo, la actividad científica española fue un prolongamiento de lo hecho en el siglo anterior, sin presentarse mayor eco en España de las novedades que se estaban produciendo; en el segundo período, que va de los años cuarenta hasta los ochenta, hay una aislada y fragmentaria introducción de algunos elementos modernos como meras rectificaciones de detalle a las doctrinas tradicionales; en el tercero y último periodo, que comprende las dos últimas décadas del siglo, «se produjo un movimiento de ruptura con el saber tradicional y sus supuestos. A partir de una conciencia explícita del atraso científico español, dicho movimiento renovador lanzó un programa de asimilación sistemática de la ciencia moderna, que serviría de base al periodo ilustrado» ${ }^{23}$. Si ello fue así, la reinserción de España a la llamada por Mutis «la culta Europa» no se realizó «ex abrupto» en la segunda mitad del siglo XVIII, como comúnmente se cree, sino paulatinamente por obra de los «neotéricos» de finales de siglo XVII y de los «novatores» en la primera mitad del siglo XVIII. Todo ello ocurría antes de que nos iluminara con sus luces la ilustración francesa en la segunda mitad del siglo ilustrado y de que en 1760 nos visitara el sabio Mutis.

El Breve tratado del cielo y de los astros, que vamos a analizar, es el fruto de unas lecciones dadas por Mimbela a sus alumnos del segundo curso de artes en la Universidad Javeriana en el año 1693, en las cuales comenta como era costumbre el clásico tratado aristotélico De caelo. Se inscribe, por tanto, dicho texto dentro de la tradición, pero en un periodo de innovación, que explica por qué Mimbela cita a Nicolás Copérnico y a Tycho Brahe y (lo que es más importante) que su autor muestre un amplio conocimiento de las observaciones más recientes realizadas por Galileo, aceptando algunas de las consecuencias innovadoras que de tales hechos se desprendían. Si esto es verdad, Mimbela está situado entre la tradición y la modernidad. Damos, pues, en este libro un nuevo paso en la dirección que busca limpiar de prejuicios la mirada hacia el pasado.

\section{La revolución copernicana}

A manera de antecedentes históricos que nos ayuden a comprender el fondo tradicional y las posibles novedades del texto de Mimbela, hacemos a continuación un sucinto recuento de

22 ORTEGA Y GASSET, José. Obras Completas. Madrid, Revista de Occidente, 1960-1962, t. IX: Una interpretación de la historia universal. En torno a Toynbee, cap. 7, pp. 132-133 y 139. Ortega achaca «esta enfernedad que fue la hermetización de nuestro pueblo hacia y frente al resto del mundo» no sólo a causas naturales de la evolución de los pueblos, sino también al Concilio de Trento, órgano de la Contrarreforma, que en los demás países de Europa impuso un orden y una disciplina de la que estaban necesitados, pero que «donde sí causó daño definitivo fue precisamente en el pueblo que la emprendió y dirigió, es decir, en España [...] España era el único país que no sólo no necesitaba Contrarreforma sino que ésta le sobraba. En España no había habido de verdad Renacimiento ni, por tanto, subversión». Obras Completas, t. VIII: La idea de principio en Leibniz, p. 355.

23 LÓPEZ PIÑERO, José María. Ciencia y técnica en la sociedad española de los siglos XVI y XVII. Barcelona, Labor Universitaria, 1979, p. 377. 
los momentos más importantes de la llamada revolución copernicana, cuyos principales protagonistas fueron: Nicolás Copérnico (1473-1543), Tycho Brahe (1546-1601), Juan Kepler (1571-1630), Galileo Galilei (1564-1642) e Isaac Newton (1642-1727) ${ }^{24}$.

De acuerdo con el viejo sistema de Ptolomeo, antes de la revolución copernicana, se suponía:

a) Que la Tierra estaba inmóvil en el centro del universo, envuelta por los siete cielos planetarios correspondientes a la Luna, Mercurio, Venus, Sol, Marte, Júpiter y Saturno.

b) Que dichos planetas (entre los cuales se contaba el Sol) giraban al rededor de la Tierra conjuntamente con sus respectivas esferas, compuestas de una materia dura y cristalina.

c) Que la materia de dichas esferas y de los correspondientes planetas era naturaleza incorruptible y superior a la materia de las cosas del mundo sublunar, corruptibles por su propia naturaleza.

d) Que, envolviendo a los siete cielos planetarios, se encontraba el firmamento o bóveda celeste, con todas las estrellas tachonadas al mismo como los clavos a una tabla, girando con ella al rededor de la Tierra

e) Que el movimiento en torno a la Tierra de las diversas esferas y de los astros correspondientes era perfectamente circular y uniforme.

f) Finalmente, los pensadores cristianos imaginaban en el último y más elevado lugar, coronando toda esta imaginaria máquina del universo, el llamado cielo Empíreo, morada de Dios y habitáculo de los bienaventurados.

Así las cosas, en 1543 aparecía en Nüremberg el libro del canónigo polaco Nicolás Copérnico De revolutionibus orbium caelestium. En esta obra se atreve Copérnico a mover dos de las piedras angulares del viejo sistema, poniendo al Sol en el centro del universo y convirtiendo a la Tierra en un planeta más entre los siete que giraban en torno al nuevo centro solar. Es cierto que el resto del sistema de Ptolomeo quedaba intacto, pero el cambio operado era tan profundo, que le costaría tiempo y trabajo al hombre, que se consideraba rey y centro de la creación, pensar que su casa era un planeta descentrado y errante. A partir de este momento, la antigua «imago mundi» se va a ir desmoronando pedazo a pedazo como los viejos muros, hasta quedar completamente demolida al término de un siglo de enconados debates.

Dando un paso hacia atrás, el gran astrónomo danés Tycho Brahe, volvía a poner a la Tierra en el centro del universo, por considerar el geocentrismo más de acuerdo con el sentido común y con las Sagradas Escrituras. Pero otras observaciones suyas constituían un verdadero elemento revolucionario hacia adelante. Observando que las órbitas de los cometas eran elípticas, dedujo Tycho que los cielos no podían estar compuestos de una materia dura y cristalina, porque en tal caso, no podrían desplazarse por los cielos planetarios sin romperlos; postuló, por tanto, que la materia de los cielos debía ser blanda y fluida para permitir a los astros moverse libremente como los peces en el agua o como las aves en el aire. Con estas observaciones Brahe removió otro sillar de la vieja «imago mundi». Además, para explicar los epiciclos y las órbitas excéntricas de varios planetas, supuso Tycho que excepto la Luna, el resto de los planetas (Mercurio, Venus, Marte, Júpiter y Saturno) giraban en torno al Sol, acompañándolo

24 Hay traducciones al español de las siguientes obras clásicas: PTOLOMEO, T. Las hipótesis de los planetas. Madrid, Alianza, 1987; COPÉRNICO, N. Sobre las revoluciones celestes. Barcelona, Atalayá, 1994; KEPLER, J. El secreto del universo. Barcelona, Atalaya, 1994; Conversación con el mensajero sideral. Madrid, Alianza, 1984; GALILEO GALILEI. Diálogo sobre los dos sistemas máximos. Bs. As., Aguilar, 1967; El mensajero sideral. Madrid, Alianza, 1984; Carta a Cristina de Lorena y otros escritos. Barcelona, Atalaya, 1994. Sobre la revolución copernicana hay abundante bibliografía en español: KOYRÉ, A. Estudios de historia del pensamiento cientifico. México, Siglo XXI, 1978; Estudios galileanos. Madrid, Siglo XXI, 1980; KUHN, Th. La revolución copernicana. Barcelona, Ariel, 1978; VERNET, J. Astrología y astronomia en el Renacimiento. La revolución copemicana. Barcelona, Ariel, 1974; VARIOS. Nicolás Copérnico en el quinto aniversario de su nacimiento. Bs. As., Siglo XXI, 1973. ABETTI, G. Historia de la astronomía. México, FCE, 1956. 
a éste en sus giros al rededor de la Tierra. Muchos astrónomos, como luego veremos, aunque consideraban el sistema de Tycho demasiado complicado, lo aceptaron por considerarlo más de acuerdo con la Biblia.

Definitivamente, Johannes Kepler no sólo repuso al Sol en el centro del universo, dando la razón a Copérnico, sino hizo algo más importante por lo cual lo recuerda la historia: y fue que, aceptando la teoría de la fluidez de los cielos de su maestro Tycho Brahe, pudo descubrir que las órbitas de los planetas en torno al Sol no eran circulares sino elípticas, formulando las leyes que rigen sus respectivos movimientos, de tal manera que con respecto al Sol la distancia de los planetas en su largo recorrido elíptico no era siempre la misma. Caía así otro postulado tradicional, el que las formas esféricas y circulares eran las más perfectas, resolviéndose finalmente el problema de los epiciclos.

En este contexto, Galileo, con la ayuda del «tubo óptico» o telescopio, pudo confirmar tan admirables descubrimientos y contemplar lo que hasta entonces nadie había podido ver con los ojos:

Que, observada la galaxia con el anteojo, se resolvía en una ingente muchedumbre de estrellas, distribuidas en grupos llamados constelaciones; y que también las nebulosas eran en realidad rebaños de estrellas.

a) Que la superficie del Sol presentaba manchas cambiantes y que la superficie de la Luna no era plana y lisa como se creía, sino escarpada y desigual, estando cubierta como la Tierra de «promontorios, valles y anfractuosidades».

b) Que además de los siete planetas que giran en torno al Sol, otros cuatro de menor tamaño giraban en torno a Júpiter.

c) Que Saturno estaba ceñido de anillos y Marte y Venus presentaban fases similares a las de la Luna.

Estas y otras observaciones provocaron la caída de los dos últimos sillares en los que se apoyaba la vieja imagen del universo: la materia de los astros no podía ser, como se creía, incorruptible; y, algo más importante, el universo aparecía ahora como un espacio abierto a dimensiones infinitas. Todo lo cual chocaba contra las interpretaciones que los teólogos daban de ciertos pasajes bíblicos en apoyo de la vieja imagen del mundo centrado en la Tierra, cerrado por la bóveda celeste y, por tanto, finito. Para defenderse de los teólogos con sus mismas armas, Galileo se vio forzado a hacer sus propias reflexiones epistemológicas y hermenéuticas en torno a la naturaleza de la ciencia y la teología. Según el sabio florentino la ciencia nos enseña «cómo va el cielo», la teología «como se va al cielo». Los autores de las Sagradas Escrituras hablan del Sol, la Luna y las estrellas según las apariencias, sin haber tenido nunca la pretensión de enseñarnos astronomía. «Me parece, escribe Galileo, que en las disputas acerca de los problemas naturales no habría que comenzar por la autoridad de los pasajes de las Escrituras, sino por las experiencias sensatas y las demostraciones necesarias». Fueron precisamente estas consideraciones revolucionarias para su tiempo, y que hoy son de común recibo, las que de modo especial irritaron a los hombres de iglesia, que no podían entender cómo un seglar les podía dar lecciones de interpretación bíblica a los teólogos. Para evitar este tipo de confrontaciones, el Cardenal Belarmino aconsejaba a Galileo hablar del nuevo sistema «ex suppositione», es decir, como hipótesis posible, pero sin ninguna relación con la realidad de hecho de nuestro mundo. Pero le quedaba difícil a Galileo poner entre paréntesis lo que veía con el telescopio e imposible negar los hechos. En definitiva, se produjo el choque entre las dos mentalidades, la tradicional y la moderna, que desembocó en el juicio a Galileo y en la condena del heliocentrismo en un triste día para la ciencia y para la Iglesia: el 22 de junio de 1633. También los reformadores, Lutero y Calvino, habían condenado antes que la Roma el sistema copernicano como contrario a las enseñanzas bíblicas. Thomas S. Kunh resume admirablemente la situación vivida: 
movimiento terrestre. Con frecuencia siempre en aumento los copernicanos recibia los epitetos de infieles y ateos, y cuando al rededor de 1910 la Iglesia católica se adhirió oficialmente a la batalla contra el copernicanismo, el cargo pasó a ser de pura y simple herejía. En 1616 fueron puestos en el Índice el De revolutionibus y todas las obras en que se admitía el movimiento de la tierra. Se prohibió a los católicos enseñar, e incluso leer, las teorías copernicanas, salvo en versiones expurgadas de toda referencia a una tierra en movimiento y a un sol central».

«A mediados del siglo XVII es difícil encontrar un gran astrónomo que no sea copernicano, a finales del mismo siglo es imposible. La astronomía elemental reaccionó más lentamente. Con todo, durante las últimas décadas del siglo se enseñaban simultáneamente los sistemas de Copérnico, Ptolomeo y Brahe en muchas universidades protestantes de primera fila. Durante el siglo XVIII fueron gradualmente abandonados los cursos sobre los dos últimos sistemas citados. Por lo que respecta a la astronomía popular, fue el campo que recibió con mayor lentitud el impacto del copernicanismo. Hubo que dejar transcurrir la mayor parte del siglo XVIII para dotar al pueblo y sus maestros de un nuevo sentido común y para convertir el universo copernicano en una propiedad colectiva del hombre occidentals ${ }^{25}$.

Teniendo en cuenta este marco histórico de la llamada revolución copernicana, vamos a. entrar a analizar los aspectos tradicionales y los modernizantes del Tratado del cielo y los astros de Mateo Mimbela, que es el objetivo específico que nos hemos propuesto en este estudio.

\section{ANALISIS DEL «BREVIS TRACTATUS»}

Dentro de la tradición aristotélico-escolástica, el tratado De coelo (Peri ouranou) era el complemento natural del curso de la física, ofreciendo a los estudiantes una imagen completa del mundo, de acuerdo con los adelantos de la época. Ciertamente, la imagen que ofrece Mimbela a finales del siglo XVII está todavía anclada en la tradición, pero en algunos aspectors se asoma a la modernidad y la acepta. Sus contenidos se hallan divididos en seis cuestiones, subdivididas a su vez algunas de éstas en secciones del modo siguiente:

Cuest. $1^{a}$ : Si los cielos están animados.

Sec. $1^{a}$ : Los cuerpos celestes están desprovistos de cualquier clase de alma.

Sec. $2^{a}$ : Distinción especifica de los cuerpos celestẹs y sublunares.

Cuest. $2^{a}$ : Si los cielos son corruptibles por su propia naturaleza.

Cuest. $3^{a}$ : Si los cielos son fluidos o sólidos.

Cuest. $4^{a}$ : Sobre el número de cielos y astros, su figura y magnitud.

Sec. $1^{a}$ : Se expone la multiplicidad de los cielos.

Sec. 2a: Se explica la figura y la magnitud de los cielos.

Cuest. 5a: Sobre el movimiento de los cielos y de los astros.

Cuest. $6^{a}$ : En la que se resuelven algunas dificultades.

Antes de entrar al análisis de cada una de las anteriores cuestiones; se imponen unas consideraciones generales sobre lo tradicional y lo moderno del tratado, que ayuden a la lectura e interpretación del mismo. Lo más tradicional y caduco en Mimbela es que intente una y otra vez probar sus conclusiones en primer lugar con textos bíblicos, cuando las Sagradas Escrituras hablan según las apariencias y de acuerdo con concepciones cosmogónicas de los pueblos del Oriente Medio, en las cuales se inserta la revelación de Dios. Hoy, instalados en una mentalidad científica y con mejores conocimientos del mundo bíblico, nos parece increíblemente ingenuo, pseudocientífico y antibíblico dicho uso argumentativo, que perduró en la Iglèsia $\mathrm{Ca}$ - 
tólica hasta bien entrado nuestro siglo y que todavía está vigente en no pocas sectas cristianas fundamentalistas. Lo que Galileo, antes que nada, intentó cambiar fue el viejo modo de leer la Sagrada Biblia, por otro nuevo que no frenara el avance de las ciencias, sin muchos resultados por el momento a juzgar por la posterior historia de la exégesis bíblica.

Otro aspecto ciertamente positivo, que llama la atención en su obra, es lo bien informado que estaba Mimbela sobre las nuevas teorías del mundo y las observaciones en las que se basaban. Podrá estar o no de acuerdo el maestro javeriano con los matemáticos y astrónomos de su siglo, pero lo cierto es que los tiene en cuenta en sus argumentaciones y hasta los cita por sus nombres propios. En la temprana fecha de 1693 nombra una vez a Nicolás Copérnico, haciéndose eco de su sistema, y dos veces a Tycho Brahe, a quien sigue en puntos importantes. Más aún, aunque no nombra a Galileo, reconoce la importancia del «tubo óptico» con el que el sabio florentino observó las manchas del Sol, los montes y los valles de la Luna, los satélites de Júpiter y de Saturno, la Vía Láctea y las nebulosas, etc. Todo lo cual demuestra, al menos, que las nuevas teorías cosmológicas fueron expuestas por primera vez en el Nuevo Reino sesenta y siete años antes de que Mutis desembarcara en Cartagena de Indias. Esto supuesto, vamos a analizar en particular cada una de las cuestiones planteadas por Mimbela.

\section{Si los cielos están animados y si se distinguen entre sí y con relación a los astros}

Esta primera cuestión gozaba en los tiempos de Mimbela de cierta actualidad, dado que pensadores tan importantes como Campanella, Telesio y Bruno, entre otros, pusieron de moda en el siglo XVI el viejo panpsiquismo, que concebía el universo como un inmenso organismo dotado de sentidos e incluso de una alma racional, la llamada «anima mundi» ${ }^{26}$. En contra de dicho pansiquismo, defiende Mimbela que «los cielos carecen de toda clase de vida», puesto que se mueven por obra de un motor extrínseco. Pero, aunque los cielos se movieran por sí mismos, ello no sería razón suficiente para concederles vida, ya que los cuerpos pesados y livianos, pese a moverse por sí mismos hacia abajo o hacia arriba, carecen de vida. En este punto Mimbela recurre para probar su tesis a un argumento de razón, tomando en cuenta las observaciones de Galileo:

«Para ejercer sus operaciones vitales los cuerpos vivientes requieren una organización, que no la percibimos en los cielos, porque no es obligado admitir que los promontorios, los canales y los orificios, descubiertos en el Sol y en la Luna por los modernos matemáticos, sean los órganos de dichos astros» (n.3).

Pero negada la cuestión «de hecho», ello no implica que haya que negar forzosamente la cuestión «de posibilidad». Mimbela afirma que la hipótesis de la animación de los cielos no es en absoluto absurda o imposible, porque no hay razón alguna para pensar que si Dios puede hacer cuerpos tan grandes como los astros, no pueda crear para los mismos un alma de la misma magnitud.

Otra cuestión muy distinta es la de si existe en otros astros alguna clase de vida, como la hay sobre la Tierra; y, más concretamente, si la Luna o otros planetas están habitados por seres racionales. En cuanto a si hay vida en general, cuestión hoy de actualidad, Mimbela admite la posibilidad de vida extraterrestre; pero, en particular, a la cuestión de si hay vida humana en la Luna, responde Mimbela negativamente, planteando desde una interpretación bíblica literal propia de su tiempo, las siguientes preguntas teológicas:

26 En nuestros días el pansiquismo ha tenido un brillante defensor en el eminente astrónomo inglés HOYLE, Fred, El universo inteligente. Barcelona, Grijalbo, 1984. 
« ¿Esos supuestos hombres fueron engendrados a partir de Adán, o de otro hombre creado por Dios en la Luna? Si lo primero, ¿cuándo ascendieron a la Luna y qué Apóstol fue enviado a predicarles el evangelio y enseñarles los sacramentos $o$, acaso, son tan desgraciados que carecen de este bien inefable? Si lo segundo, ¿cómo es posible que Moisés, que reseñó cuidadosamente todo lo referente a la creación del mundo, no se acordara de dichos hombres, sino tan sólo de los adámicos?» (n. 6).

En la segunda parte de la cuestión se pregunta ¿de qué están hecho los cielos? Y responde que, por ser materiales, los cielos se componen, al igual que las cosas del mundo terrestre, de materia prima y de formas substanciales. Pues bien, en este punto Mimbela se atreve a contradecir a la tradición aristotélica, sosteniendo que la materia de los cielos (exceptuando el Empíreo) es de la misma especie que la materia de las cosas sublunares, opinión que dejaba abiertas las puertas a la tesis de la intrínseca corruptibilidad de la materia celeste. No obstante, siendo las formas celestes, que informan dicha materia común, superiores y más bellas que las sublunares, hacen que lo que de suyo es intrínsecamente corruptible, se torne en extrínsecamente incorruptible. Si ello así, parece que los cuerpos celestes no pueden estar hechos de alguno de los cuatro elementos conocidos en el mundo sublunar, ni de la mezcla de ellos, sino de un nuevo elemento llamado éter, la quinta sustancia de los peripatéticos, opinión que para Mimbela es «la más común hoy entre los autores y para mí tengo que es la más clara, aunque juzgo que la opuesta no carece de probabilidad».

En una época como la de Mimbela en que se discutía sobre la esencia específica de todo, incluso si cada ángel constituía especie única, no es extraño que se pregunte sobre si los cielos y los astros difieren entre sí específicamente. Pregunta a la cual responde que, «si acaso hubiere varios cielos», éstos deben diferir entre sí específicamente y estar escalonados en orden de menor a mayor perfección. Por tanto, el cielo de la Luna por su propia naturaleza debe estar situado por debajo del cielo del Sol:

«Porque el Sol es efectivamente como el cuasi-corazón de aquel mundo superior, ya que bajo su influjo beneficioso todos los demás orbes relucen, al igual que todos los miembros del cuerpo se robustecen gracias al corazón» (n. 11).

Así mismo, los astros errantes o planetas difieren específicamente entre sí, lo cual se muestra por los distintos efectos que cada uno de ellos produce, para cuya descripción recurre Mimbela al sentido común y al saber astrológico de la época, comúnmente aceptado:

«El Sol tiene una luz muy intensa, que proyecta a los demás astros; Saturno difunde calor y sequedad, lo cual incita a la guerra, siendo por lo mismo llamado Dios de las guerras; Venus, que aumenta y anima la sangre, es considerado el padre de la alegría y de la lujuria y es, por ello, impúdico; Mercurio infunde agudeza de ingenio, de la que tan necesitados están los escolásticos y los mercaderes, siendo en consecuencia considerado su Dios. La luna, en fin, proyecta humedad, dominando en las plantas»(n. 12).

Finalmente, considera Mimbela que también los astros difieren de los cielos en los que se mueven, ya que no son parte integrante de los mismos, sino seres completos en sí y adecuadamente distribuidos; también las estrellas fijas se distinguen específicamente del cielo sidéreo en el cual están clavadas y, por supuesto, de las estrellas errantes o planetas. No obstante, relativizando la tesis anterior, concluye Mimbela que «no existe razón alguna convincente para excluir la posibilidad de que existan estrellas de la misma especie».

\section{Si los cielos por su propia naturaleza son corruptibles}

Esta segunda cuestión ésta relacionada con la anterior. En ella afirma Mimbela que Dios podría corromper o aniquilar los cielos, con sólo retirarles su acción conservativa; pero no es 
éste el problema planteado, pues de lo que se trata es de saber si los cielos todos (excepto el Empíreo que por supuesto es incorruptible) son corruptibles «por su propia naturaleza».

Pues bien, desde la más remota antigüedad se habían enfrentado dos opiniones: para la mayoría los cielos eran de naturaleza incorruptible, mientras que una minoría sostenía que la materia de los cielos era tan corruptible como la de la propia Tierra. En este punto afirma Mimbela que ambas opiniones son defendibles y que cuentan a su favor con argumentos de razón y con grandes autoridades, aduciendo a favor de la corruptibilidad de la materia celeste el hecho de que «alguna vez ocurrieron en el cielo transmutaciones substanciales», a saber:

«En el año de 1572 apareció en la constelación de Casiopea una nueva estrella, que durante dos años se fue desvaneciendo paulatinamente. $Y$ no se diga que esta estrella fue un cometa existente en la suprema región del aire, ya que fue vista desde diversas partes de la Tierra siempre en el mismo lugar y con la misma magnitud» (n. 25).

En efecto, en noviembre de dicho año 1572 apareció en el cielo un astro que igualaba a Venus en brillo, y que posteriormente se fue desvaneciendo. Tycho Brahe estudió las diversas fases de este fenómeno, concluyendo que era una nueva estrella sita en la constelación de Casiopea. «Hoy sabemos que se trata de astros de resplandor relativamente débil, que de pronto, en el intervalo de pocas horas, como consecuencia de una verdadera explosión de toda la esfera gaseosa que los constituye, se vuelven luminosísimos para volver poco a poco a resplandor primitivo» ${ }^{27}$. Esta estrella hoy sería catalogada como «super nova». Sin embargo, recuerda Mimbela, que para los autores de la opinión contraria este y otros hechos no son fenómenos naturales sino hechos portentosos, que suele efectuar Dios para amonestar a los hombres sobre algún peligro inminente; concretamente, la aparición de la anterior estrella la interpreta el $\mathrm{P}$. Hurtado, como anuncio de la muerte del Rey Sebastián de Portugal en batalla de su armada contra los mahometanos en el norte de Marruecos ${ }^{28}$. Un segundo argumento a favor de la corruptibilidad de los cielos aduce Mimbela, sacado de las más recientes observaciones hechas por Galileo:

«Se prueba [la corruptibilidad] por varias mutaciones que los matemáticos han observado en el Sol y en la Luna mediante el tubo óptico. Porque afirman que frecuentemente ven en el Sol algunas manchas de las cuales unas desaparecen pronto, pero otras permanecen por largo tiempo, hasta que finalmente desaparecen; y en la Luna contemplan diariamente valles, montes, cavidades y precipicios, que no pueden provenir de otra causa, sino de la permanente generación de nuevas partes o de la corrupción de otras, por cuya defección aparecen aquellas cavidades»(n.26).

Admitidos estos hechos, punto seguido recuerda Mimbela las explicaciones que de los mismos habían dado años antes dos eminentes jesuitas, relativizando la fuerza conclusiva de los mismos en contra de la incorruptibilidad de la materia celeste. Uno de ellos el P. Cristóforo Clavio (1538-1612), profesor de matemáticas en el Colegio Romano y encargado por Gregorio XIII de la reforma del calendario cristiano, aprobada finalmente en 1582; por sus conocimientos matemáticos era considerado «el segundo Euclides» o el «Euclides de su siglo» y con la ayuda del telescopio pudo comprobar la existencia de los satélites de Júpiper, descubiertos por Galileo, a quien felicitó epistolarmente por dicho descubrimiento ${ }^{29}$. Sin embargo, no coincidía en sus explicaciones sobre la naturaleza de los accidentes observados en la superficie lunar

27 ABETTI, G. Historia de la astronomia. México, FCE, 1949, p. 108.

28 HURTADO DE MENDOZA, Pedro. Disputationes a Summulis ad Metaphysicam. Vallesoleti, 1615, Cf. Disp. 1, Sec. 15. Esta obra, consultada por Mimbela, tuvo otras ediciones con el título de Philosophia universa.

29 Lettres á Galilée, en Opere di Galileo Galilei, Firenze, 1851, vol. VIII, pp. 3, 4 y 120. La temprana muerte de Clavio privó a Galileo de un amigo y un posible defensor. SOMMERVOGEL, t. VI, col. 1796-1805. 
con Galileo: mientras que para éste lo que veía eran montañas, valles y anfractuosidades reales, Clavio replicaba que se trataba de simples fenómenos ópticos, como lo recuerda Mimbela:

"Acerca de las cavidades y promontorios de la Luna hay quien replica, que si los vemos siempre en la misma parte de la Luna, no por ello se puede inferir que la superficie de la misma sea áspera y dispareja, en vez de plana y tersa; tampoco que el cielo sea corruptible. Por tanto, no probado lo anterior, se puede decir que las partes externas de la Luna unas son diáfanas y claras y otras en cambio opacas y oscuras. Ahora bien, dado que un cuerpo diáfano no opone resistencia a la vista, antes bien le ofrece vía libre hacia el fondo opaco, ocurre con frecuencia que no percibimos el cuerpo diáfano antepuesto al opaco, sobre todo si está distante. De lo cual resulta que en la parte diáfana y clara no vemos nada, mientras no llegamos a su interior opaco y, por lo mismo, nos parece que hay cavidades en ella. En cambio, cuando las partes son opacas se distinguen fácilmente en su propio lugar y por ellos nos parecen que fueran montes prominentes»(n. 28).

El P. Cristóforo Scheiner (1575-1650), profesor de matemáticas en Ingolstadt, Friburgo de Brisgovia y Roma, había descubierto las manchas solares años antes que Galileo hablara de ellas $^{30}$; no obstante, para este sabio jesuita dichas manchas solares no existían realmente en la superficie solar, sino que eran así mismo un fenómeno óptico producido por la interposición de pequeños astros entre el Sol y la Tierra, tal y como lo recuerda Mimbela:

«Las manchas solares [según Scheiner] no existen en el Sol mismo, sino que son más bien ciertos cuerpos densos y opacos, que estando frente al Sol, de tal manera oscurecen su luz, que a nosotros nos parece manchado. Estos corpúsculos no están por debajo de la Luna, sino por encima de ella y son a modo de estrellitas más densas que aquellas partes del cielo, en el que se mueven al rededor del Sol»(n.27).

Se trataba de dos explicaciones especiosas e infundadas, que pretendían mantener en pie la vieja tesis de la incorruptibilidad, pero que no podían por más tiempo desvirtuar las consecuencias de los hechos descubiertos. La realidad una vez más se imponía echando definitivamente abajo el imaginario platónico de un doble mundo, el sublunar de las cosas corruptibles y el superior de las cosas incorruptibles. Mimbela, frenado por la prudencia, no se atreve a aceptar las consecuencias derivadas de las observaciones de Galileo, para terminar diciendo sin mucha convicción, que «nuestra opinión se inclina más hacia la primera sentencia», a saber: que los cielos son incorruptibles, pero no por razón de la materia prima, que es de por sí corruptible, como antes nos dijo, sino en virtud de las formas celestes, que informan dicha materia, defendiéndola extrínsecamente de la corrupción que le es propia.

\section{Si los cielos son fluidos o si son sólidos}

Siguiendo a Aristóteles, los escolásticos admitían como doctrina tradịcional que los cielos eran esferas sólidas y cristalinas, que giraban en torno a la Tierra con los respectivos astros en ellas instalados. Mimbela se desmarca en este punto de la tradición, haciendo suya la opinión de «Tycho Brahe y del Padre Nieremberg, aceptada entre los más recientes astrónomos». Sostiene, por consiguiente, «que todos los cielos planetarios son fluidos a la manera del aire y que los astros se mueven en ellos como los peces en el agua y las aves en el cielo». Aunque esta cuestión hoy nos parezca anacrónica, en su tiempo fue el principal aporte que Thy-

30 Tres epistolae de maculis solaribus scriptae ad Marcum Velserum. 1612, reimpresas en Opere di Galileo Galilei, vol. III, pp. 272-380. SOMMERVOGEL, t. VII, col. 734-743 
cho Brahe hizo a la revolución astronómica, sin el cual Kepler no hubiera podido formular las leyes que rigen el movimiento de los planetas en órbitas elípticas. Mimbela en este punto está abierta y decididamente con los astrónomos modernos:

\begin{abstract}
"Que el cielo de los planetas es fluido se prueba ciertamente por las observaciones que han hecho peritísimos astrónomos, a los que no es lícito negarles fe. Estos, en efecto, afirman que con la ayuda del tubo óptico (en español mira o anteojo de larga distancia) han captado que Venus, Mercurio y Marte unas veces ascienden por encima del Sol y otras descienden por debajo; unas veces se mueven hacia una de sus partes y otras hacia la contraria. Lo cual ciertamente no podría suceder, si los cielos fueran sólidos, sin que se hicieran añicos los planetas o sin que éstos quedaran bloqueados en los cielos, sobre todo si a cada uno de los planetas se les asigna un cielo, como muchos adversarios lo aseveran. En cambio, si se supone que el cielo es fluido y blando, entonces tales fenomenos se explican fácilmente; pues siendo el cuerpo fluido fácilmente penetrable, los planetas se moverian sin dificultad ya hacia arriba o hacia abajo, o bien hacia los lados del Sol, como las aves que volando ascienden y descienden por el aire formando variados coros, sin que queden bloqueadas en el aire»(n. 35).
\end{abstract}

Los que sostenían la opinión contraria replicaban que si las pequeñas aves producen no pequeño ruido cuando vuelan, qué ruido no producirían los astros en caso de navegar en un medio fluido; pero, dado que no producen ruido, hay que concluir que los cielos no son fluidos. A los cuales replica Mimbela, que una persona que nada por debajo de la superficie del agua no produce ruido, pero «aun dado que los planetas produzcan grandísimo sonido, no lo oímos por estar a demasiada distancia». A propósito y no sin cierta ironía recuerda Mimbela que a Pitágoras y a otros muchos filósofos y poetas les quedó sonando bellamente en sus oídos la supuesta «música astral o celestial» ${ }^{31}$.

La fluidez de los cielos era una tesis que se imponía, desde que Tycho Brahe descubrió que las órbitas de los cometas eran elípticas y que, por consiguiente, al penetrar en los cielos planetarios los volverían añicos en caso de ser éstos sólidos y cristalinos. Pese a todo, el jesuita inglés Tomás Compton (1591-1666), profesor de filosofía y teología en el Collegium Anglorum de Lieja, seguía defendiendo la solidez de las esferas celestes, porque «in caelorum fabrica magis elucet sapientia Dei, si sphaerae omnes sint solidae» ${ }^{32}$. Pero dejando aparte los cometas, el mismo efecto catastrófico se produciría por obra de Mercurio y Venus, ya que a estos planetas se les podía ver subir y bajar con respecto a la órbita del Sol. Para obviar tal dificultad, Compton afirmaba que estos dos astros giran directamente en torno al Sol, asumiendo en parte las teorías de Tycho Brahe:

«Mercurio y Venus no tienen esferas propias por debajo de la del Sol, como ciertamente opinan los astrónomos, sino que realizan en la propia esfera del Sol algunos epiciclos o giros al rededor del mismo. Por tanto, mientras estos dos planetas se mueven de oriente a occidente juntamente con el Sol, arrastrados por su movimiento, al mismo tiempo Mercurio y Venus con su peculiar movimiento se mueven en estos círculos o epiciclos del septentrión al medio día, dando vueltas al rededor del Sol» ( $n$. 77).

Replica Mimbela que no salva la dificultad, puesto que también a Marte, planeta al que Compton le asigna una esfera propia en torno a la Tierra, se le ha visto subir y bajar; por tanto,

31 Fray Luis de León en la «Oda a Francisco de Salinas» recuerda como la música de este gran maestro renacentista eleva el alma, hasta el punto que: «Traspasa el aire todo / hasta llegar a la más alta esfera / y oye allí otro modo / de no perecedera / música que es la fuente y la primera».

32 Philosophia universa, Antuerpiae, 1649. Mimbela manejó esta obra, en la que es citado Tycho Brahe «In libros de Caelo», pp. 397-311. SOMMERVOGEL, t. I, col. 1354-1355. 
se produciría el mismo choque violento que trataba de evitar poniendo a girar a Mercurio y Venus en torno al Sol. Para obviar esta nueva dificultad, el también jesuita Juan Bautista Riccioli (1598-1671), profesor de teología en Parma y Boloña ${ }^{33}$, que al igual que Compton defendía la solidez de los cielos, puso a girar también a Marte en la órbita del Sol. Estas explicaciones no le convencen a Mimbela:

«Es preferible decir, con la opinión más común y plausible en estos tiempos, que el cielo de los planetas es fluido, antes que caer en aquella singular opinión [Riccioli] que asigna a la Luna, Júpiter y Saturno tres cielos, y un único cielo común al Sol, Mercurio, Venus y Marte» (n. 38).

En Cambio, siguiendo la tradición, considera Mimbela que el cielo sidéreo o firmamento es una esfera sólida a la que están tachoṇadas las estrellas, las cuales se mueven juntamente con ella, «como los clavos de una tabla que se mueven con la tabla». La razón que esgrime Mimbela es porque los modernos matemáticos no ofrecen pruebas de peso en contra de la solidez del cielo sidéreo o bóveda celeste; además, Mimbela aduce una curiosa razón de economía divina, a saber: que a Dios le complace, cuando ello le es posible, delegar funciones. Por esta razón, puso Dios un ángel a cada planeta para dirigir adecuadamente su curso. Hasta aquí no veía problema alguno. Pero, ¿qué pasaría si el cielo de las estrellas fuera fluido? Que cada una de las infinitas estrellas se movería con independencia de las demás, lo cual exigiría

«la existencia de una numerosísima multitud de ángeles destinada a tal oficio, a todas luces superflua dado que fácilmente se podría solucionar el problema con un solo ángel que moviera simultáneamente la esfera celeste y con ella las estrellas fijas a la misma, de modo similar a como los clavos de una tabla se mueven juntamente con la tabla» (n. 39).

El recurso a ángeles y demiurgos para la ordenada conducción del mundo tiene raíces muy hondas en el pasado. Impresiona la cantidad de páginas que a estas supuestas inteligencias superiores dedica Santo Tomás en la Summa Theologiae; la angeología ocupa en dicha obra un total de 15 cuestiones con 72 artículos, en las cuales el merecidamente llamado Doctor Angélico parece saberlo todo. En cuanto a su cantidad, afirma que «por ser sustancias inmateriales, existe un número máximo de ángeles, tal que excede la multitud.de las cosas materiales» ${ }^{34}$. No piensa así Mimbela, a quien le parece demasiado despilfarro suponer la existencia de tantos ángeles como estrellas, prefiriendo por razón de economía divina que un solo ángel mueva el cielo sidéreo con todas las estrellas, estando como están sujetas a él como los clavos a una tabla. Frente a tan exuberante milicia angélica, otro jesuita que leyó física en la Universidad Javeriana en el curso de 1755 , establece con gran sentido del humor la siguiente analogía entre lo que hacen los filósofos y los pintores barrocos:

«Hacemos [los filósofos] como los pintores, quienes para cada oficio servil escogen ángeles, de tal modo que si es necesario ofrecer a alguien un ramo, lo ofrece un angel; si hay que sostener la cabeza de alguien que duerme, la sostiene un ángel; si hay que espantar las moscas a un niño, las espanta un ángel, etc.» ${ }^{35}$.

33 Escribió Almagestum Novum Astronomiam veterem novamque complectens, 3 vols. Bononiae 1651; Astronomia reformata, Bononiae, 1665. SOMMERVOGEL, t. VII, col. 734-740.

34 Summa Theologiae I, qq. 50, a. 3.

35 Physica specialis et curiosa (anónimo de 1755). Bogotá, USTA, 1988, p. 60. 


\title{
4 Sobre el número y figura de los cielos y astros
}

A Mimbela le parece excesiva la opinión tradicional, que admitía la existencia de once cielos escalonados de menos a más en este orden: 1) el de la Luna; 2) el de Mercurio; 3) el de Venus; 4) el del Sol; 5) el de Marte; 6) el de Júpiter; 7) el de Saturno; 8) el cielo de las estrellas fijas o firmamento; 9) el llamado cristalino; 10) el primer móvil; 11) y finalmente el cielo Empíreo, que es «la curia de Dios y la morada de los bienaventurados». Mimbela cree que once son demasiados cielos, porque, como dice el proverbio escolástico, no hay que multiplicar los entes sin necesidad, y además porque «parece increíble que Dios haya creado tantos cielos como planetas, siendo así que el cielo en comparación con los planetas es como el mar con respecto a los exiguos peces».

En cambio, el P. Pedro Hurtado de Medoza (1578-1651), profesor de filosofía y teología en Salamanca, pendulando al extremo contrario, sostenía la existencia de un sólo cielo, en el cual estarían contenidos todos los planetas y las estrellas ${ }^{36}$. Mimbela considera esta opinión inconsistente con los principios que establecía dicho autor:

\begin{abstract}
«Porque admitiendo, como admite [Hurtado], que dicho cielo es sólido, debería conceder que los planetas penetran en él o que están hecho en su mayor parte de canales. Lo primero es imposible; lo segundo falso, porque se requeriría que aquellos grandes canales, por los que supuestamente giran los planetas [como los gusanos por los agujeros abiertos al interior de un queso], estuvieran vacios; pero estas vacuidades no existen: luego...etc. Se prueba la menor, porque por aquel espacio que deja el Sol, cuando se mueve de oriente hacia occidente, por las noche vemos estrellas; pero ello no sucedería de quedar dicho espacio vacio, porque por el vacio no pueden trasmitirse imágenes visuales de cuerpo alguno: luego no se dan en el cielos esas supuestas cavidades o vacuidades» (n. 50)
\end{abstract}

En medio de ambos extremos se sitúa Mimbela, para quien existen «tres cielos ni más ni menos», que son el cielo planetario, el sidéreo y el empíreo. Se apoya para ello el famoso texto paulino, en el que cuenta el apóstol cómo fue arrebatado hasta el tercer cielo. Ahora bien, argumenta Mimbela que este cielo no puede ser el tercero de la serie anterior de once, o sea, el cielo de Venus:

«Porque, pregunto, ¿qué haría el Apóstol en el cielo de Venus, qué podría ver sino el mismo planetilla que por las noches vemos desde la Tierra? Ni hablar, el Apóstol fue elevado al cielo Empireo, para que alli oyera palabras imposibles de comunicar al hombre» (n. 51).

No obstante que Mimbela defiende rotundamente que sólo existen tres cielos «ni más ni menos» (el cielo de los planetas, el de las estrellas y el empíreo de Dios y sus santos), en los párrafos sin numerar que siguen al n. 51, parece poner en duda dicha tesis, afirmando que encuentra «gran dificultad en que el cielo de los planetas sea tan sólo uno». Considero, por mi parte, que se resuelve fácilmente esta aparente contradicción, suponiendo que ambos párrafos innumerados no pertenecen al texto original, sino que fueron añadidos por el copista a modo de objeción a la enseñanzas de Mimbela, apoyándose en el siguiente fenómeno astronómico recientemente vivido:

«Porque en esta ciudad de Santafé el día 23 de agosto del año del Señor de 1691 la Luna cubrió el Sol hasta el punto de no verse en absoluto; pero no lo hubiera cubierto si la luna estuviera en el mismo cielo [con el Sol]: luego no se encuentra en el mismo cielo en el que está el Sol»(n. 51 bis). 
En cuanto al número de estrellas, afirma Mimbela que todos los astrónomos convienen en que las conocidas suman un total de 1.022; pero, haciéndose eco de los recientes descubrimientos de Galileo, añade que existen un número casi infinito de estrellas en las galaxias y las nebulosas, que no pueden ser visualizadas a simple vista, pero sí contempladas con la ayuda del tubo óptico o telescopio. Espectáculo grandioso, difícilmente conciliable con la imagen tradicional de un mundo finito. Otra prueba más de que Mimbela estaba al día de los descubrimientos hechos por Galileo es que, hablando del número de los planetas, afirma taxativamente que:

«Las principales estrellas errantes [planetas] son siete, a las que ciertamente hay que añadir otras cuatro, llamadas joviales, porque giran en torno a Júpiter [Jovis], y otras dos que acompañan a Saturno» (n. 54).

\section{Sobre el movimiento de los cielos y de los astros}

Era el problema central planteado por Copérnico en el siglo XVI y que continuó debatiéndose apasionadamente en el siglo XVII: ¿es la Tierra el centro del universo (geocentrismo), en torno al cual giran todos los demás astros, o este privilegio lo ostenta el Sol (heliocentrismo)? En este punto, como no podía ser de otro modo, dada la reciente condenación de las tesis defendidas por Galileo, Mimbela toma partido a favor de la doctrina tradicional afirmando:

«En contra de Nicolás Copérnico, seguidor de Protágoras y Aristarco, es por demás cierto que son los astros los que se mueven y no la Tierra, como consta por muchos lugares de la Sagrada Escritura anteriormente citados, en los cuales se atribuye el movimiento siempre a los astros y nunca a la Tierra»(n.60).

A parte de esta referencia a los textos de la Sagrada Escritura, que habían servido a los teólogos de base argumental para condenar a Galileo, Mimbela ofrece a favor del geocentrismo una razón sacada de la experiencia, curiosamente afín a aquella que aducía el también anticopernicano Tycho Brahe. Argumentaba el sabio danés que, en la hipótesis de que el movimiento de la Tierra en tormo al sol fuera real, el trayecto recorrido por una bala disparada hacia el oeste tendría que ser más largo que el de otra bala disparada con la misma fuerza hacia el este, porque en el primer caso la tierra se mueve en dirección opuesta a la bala, mientras que en el segundo lo hace en la misma dirección; pero dado que no sucede tal cosa, como es comprobable empíricamente, luego la Tierra no se mueve. En forma similar argumentaba Mimbela:

«Si la Tierra se moviera y no los astros, se seguiría que cuando alguien lanza con gran impetu una flecha directamente hacia arriba, no caería en la Tierra o sobre quien la disparó, sino en un lugar distante, como ocurre cuando se lanza una piedra o una saeta desde una nave, si ésta se mueve velozmente, lo cual nos dice la experiencia que es falso»(n.60).

Hoy es obvio que, de no apartarnos, la flecha del caso caerá sobre nuestra cabeza, pero no porque la tierra no se mueva, sino porque se mueve con su propia atmósfera. Zanjada en esta forma la cuestión más espinosa por sus implicaciones teológicas, se pregunta a continuación Mimbela si los astros se mueven en virtud propia o si lo hacen movidos por un motor extrínseco, adoptando la segunda opinión. Pero piensa que Dios, siempre que puede, delega funciones y, por consiguiente, mueve los astros «por medio de los ángeles designados por Dios para tal oficio», como más arriba expusimos. Por otra parte, añade que el movimiento de los astros es tan necesario para la vida sobre la Tierra, que si dejaran de moverse los astros por algún tiempo, sucedería que:

«No habría generaciones anuales de plantas, de frutos y de cereales, dado que éstas exigen una determinada calidad de temperatura, la cual depende al máximo del movimiento circular, como de condición aplicante de la influencia de los astros. Si el Sol no se mo- 
viera de nuestro hemisferio, las plantas se abrasarian con su calor, y no permitiría los frutos de la Tierra»(n. 72).

Siguiendo fiel a la vieja tesis de la centralidad e inmovilidad de la Tierra, renovada por Brahe, cree Mimbela que es el Sol el que realiza un giro completo en torno a la Tierra cada 24 horas, pero añade que dicho movimiento no es, como tradicionalmente se pensaba, perfectamente circular:

«Este movimiento es regular, y establece el día natural, pero no es perfectamente circular, sino que se inclina insensiblemente unas veces hacia una parte y otras hacia otra, como cuando alguien mueve circularmente la peonza, ésta se inclina sensiblemente hacia una de las partes. Este defecto, que tiene lugar todos los días, solamente se percibe en. un espacio de tiempo de 400 años. A este movimiento lo llaman los astrónomos de trepidación, pero no es distinto del movimiento circular, como falsamente opinan algunos [...] Es el mismo movimiento circular del cielo, que no es uniforme ni totalmente circular, como lo demuestra el ejemplo de la peonza» (n. 72).

\section{Resolución de algunas dificultades}

Con la única excepción del cielo Empíreo, que es el más resplandeciente de todos como corresponde a la «curia de Dios y al habitáculo de los bienaventurados», todos los demás cielos y astros carecen de luz propia o, si la tienen, es tan tenue, que necesitan recibirla con más abundancia del Sol. La luz que emite el astro rey es una realidad de naturaleza accidental mediante la cual ilumina y calienta a la Tierra, a la Luna y otros los Planetas. Pero no solamente el Sol, también el resto de los planetas y las estrellas ejercen algún género de influencia sobre los seres sublunares:

«La Luna afecta a los cuerpos con humedad y, por lo mismo, la madera sacada en plenilunio se infecta de carcoma, porque llenándose de sabia los árboles en luna creciente, la madera de los mismos al secarse se contrae y concibe carcoma»(n. 77).

Estas y otras influencias, si bien pueden indirectamente condicionar la conducta humana, no pueden determinarla en forma directa y necesaria, puesto que pese a tales influjos permanece incólume la libertad humana, «a no ser que se lesione el órgano sensorial hasta tal punto que impida el ejercicio ordenado de la razón, como sucede en el caso de los locos y los ebrios». Por consiguiente:

«Aunque los astrólogos puedan saber que un hombre nacido en tal signo o constelación tiene tal complexión o disposición, que lo inclina hacia estos efectos o hacia otros, no obstante de ninguna manera pueden conocer los eventos futuros dependientes de la voluntad de los hombres, porque dicha complexión o disposición no tiene conexión necesaria con ellos. Y esto consta por las innumerables mentiras en las que los astrólogos han sido cogidos»(n. 80).

En cuanto a la naturaleza de la Vía Láctea y de las Nebulosas, Mimbela conoce y acepta las observaciones de Galileo:

«Los matemáticos, que han observado por medio del telescopio, afirman que se trata de una aglomeración de estrellas esparcidas por todo este tramo del cielo, las cuales por ser tan numerosas no pueden ser vistas individualmente, sino como una masa albiscente, por la tenuidad de su luz, que cuando es poco intensa blanquea. En forma semejante, aquellas estrellas que los astrónomos llaman Nebulosas, por lucir poco, son grupos de estrellas, que por su tenuidad nos mandan luz oscura»(n.81). 
Pero pese a tales evidencias, que agrandaban el universo hasta límites casi infinitos, Mimbela sigue preso en el imaginario mundo circunscrito por el cielo sidéreo o bóveda celeste. Extramuros de este mundo finito, creado a la medida humana, como la mayoría los hombres de su época Mimbela imaginaba en lo más alto el cielo Empíreo, presidiendo la creación entera con su radiante belleza:

«Lo primero que comúnmente afirman los autores es que el cielo empíreo es más luminoso y radiante que el Sol, no sólo por la parte convexa sino también por la cóncava. Pues es necesario que la sede de los santos esté rodeada de máximo fulgor. Esto se desprende de su nombre, ya que se llama Empíreo no por el ardor, sino por el fulgor que despide, como dice el Angélico preceptor o divino Tomás en la Suma teológica, I, q.66, a. 3. Sin embargo, en la superficie inferior del Empíreo hay una especie de cortina opaca [...] Porque aquella santa curia es tan excelente, que los condenados no merecerán nunca verla. Dicha cortina fue producida en el primer día de la creación, cuando todavía las tinieblas estaban sobre la faz del abismo, y arderá en el día del juicio con todas las demás esferas móviles» (n. 84).

Para terminar, hay que abonar a Mimbela, como puntos positivos: claridad en los planteamientos, amplia información sobre las teorías modernas y pulcritud en las argumentaciones a favor y en contra de las diversas teorías; como punto negativo: la interpretación literal de las Sagradas Escrituras propia de su tiempo, que concedía a la

cosmovisión bíblica un valor no sólo religioso, sino también científico, condicionando indebidamente el uso de la razón y el desarrollo de las ciencias.

\section{FUENTES DEL «BREVE TRATADO»}

Supuesto lo anterior nos preguntamos, ¿en qué fuentes se informó Mateo Mimbela para confeccionar su Breve tratado del cielo y los astros?

Hay que descartar la hipótesis de que Mimbela conociera de primera mano las obras de Copérnico, Brahe, Kepler y Galileo. En el inventario de la biblioteca del Colegio Máximo de la Compañía no figura ninguna obra de dichos autores. Por tanto, parece más que probable que conociera las teorías astronómicas modernas por expositores de segunda mano. Concretamente, hemos podido identificar dos fuentes: una, es la obra titulada Esfera en común, celeste y terráquea, Madrid, $1675^{37}$, cuyo autor es el P. José Zaragoza (1627-1679), profesor en el Colegio Imperial de los jesuitas de Madrid y eminente matemático y astrónomo; escribió además otros tratados de álgebra, geometría, trigonometría, inventó y construyó instrumentos astronómicos con los cuales observó antes que ningún otro astrónomo europeo el cometa de 1667. Su obra constituye el más importante tratado de astronomía publicado en España en el siglo $\mathrm{XVI}$, «de contenido plenamente moderno, con la única limitación importante de la cuestión de los sistemas planetarios. En ella mantiene una extremada cautela, que puede explicarse por su condición de partidario en secreto del heliocentrismo y del movimiento de la Tierra» ${ }^{38}$.

37 El título completo de la obra es Esphera en común celeste y terráquea. Autor el M. R. P. Joseph Zaragoza, de la Compañía de Jesús, Calificador de la Inquisición Suprema, Catedrático de Theología Escolástica en los Colegios de Mallorca, Barcelona y Valencia, y agora de Matemáticas en los estudios Reales del Colegio Imperial de Madrid. Primera Impressión, Año de 1675. En Madrid, Por Juan Martín del Barrrio. En la parte correspondiente a la esfera celeste trata de las siguientes cuestiones: 1) Si los cielos son simples o compuestos; 2) Si su materia es de diferente especie que la sublunar o no; 3) Si son corruptibles; 4) Si son infinitos o limitados; 5) Si son animados o inanimados; 6) Si son fluidos o sólidos; 7) Si se mueven por su virtud natural o por ministerio de los ángeles.

38 LÓPEZ PIÑERO, José María. La ciencia en la historia hispana. Madrid, Salvat, 1986, p. 46; ABELLÁN, José Luis. Historia crítica del pensamiento español. Madrid, Espasa-Calpe, 1981, t. 3, pp. 390-394. 
Las obras del P. Eusebio Nieremberg (1595-1658) constituyen la otra fuente; este sabio jesuita, aunque de ascendencia alemana, nació y vivió en Madrid hasta su muerte. Se le conoce más como gran estilista de nuestra lengua romance y como tratadista clásico de temas ascéticos; no se sabe tanto que enseñó física en el Colegio Imperial de Madrid durante catorce años y que como fruto de dichas clases publicó algunos libros sobre temas de filosofía natural: Historia naturae, Antuerpiae, 1635 y Obras filosóficas, éticas, políticas y físicas, Madrid $1664^{39}$. Pues bien, con la ayuda de las citadas obras de estos dos autores preparó Mimbela su Breve tratado del cielo y los astros, que leyó en la Universidad Javeriana en el curso de artes de 1693. Me apoyo para ello en varias razones:

Primera, porque en el inventario de la Biblioteca del Colegio Máximo de la Compañía de Santafé hay registrado un ejemplar de la primera edición (1675) de Esphera en común, celeste y terráquea; en dicho inventario figuran también hasta tres ediciones de las Obras filosóficas del P. Nieremberg: Madrid, 1651 y 1664, Sevilla 1686. Estos libros estaban, pues, al alcance de todos en la librería (que así se llamaba entonces la biblioteca) del Colegio Máximo y hoy se conservan en la Biblioteca Nacional.

Segunda, por el amplio conocimiento que Mimbela manifiesta de autores como Copérnico, Brahe, Kepler, Galileo, Clavius, Scheiner, etc., cuyas teorías no pudo conocer en sus fuentes originales, pero sí estaban ampliamente expuestas en las obras citadas de Zaragoza y Nieremberg.

Tercera, porque el maestro neogranadino coincide con ambos autores en defensa de algunas tesis modernas, a saber: negación de un alma cósmica, afirmación de una misma materia prima común para todos los cielos, oposición a la tesis de las esferas u orbes cristalinos, defensa del movimiento de los planetas en un medio celeste fluido, negación de la perfecta circularidad de las órbitas de los astros, etc. A veces defiende dichas tesis casi con las mismas palabras de dichas fuentes.

En cuanto a la cuestión central «geocentrismo versus heliocentrismo», que dividía apasionadamente a los hombres de la época, los tres jesuitas estaban, como no podían menos de estar después de la condena de Galileo el 22 de julio de 1633, del lado del geocentrismo. Pero Mimbela es más tajante que Zaragoza y Nieremberg en defensa de viejo sistema de Ptolomeo: «es completamente cierto (certissimum est) que se mueven los astros y no la Tierra», escribe Mimbela, mientras que Zaragoza relativiza su adhesión al geocéntrico (que probablemente no compartía en el foro interno), comentando que la teoría de Copérnico «es ingeniosa, pero está condenada», como quien dice: no hay más remedio que rechazarla como falsa de hecho; pero añade que, poniendo entre paréntesis los hechos, «por modo de hipótesis o suposición pueden todos valerse de ella para el cálculo de los planetas; con que sólo se condena la actual realidad de esta composición [de los cielos], pero no su posibilidad».

En otro punto, mientras Mimbela cree estar más de acuerdo con el modo de obrar de Dios el que los astros sean movidos por ministerio de los ángeles, con tal que no se abuse de su número, Nieremberg, por el contrario, se muestra escéptico sobre la necesidad de ángeles motores, que supuestamente actúan como «pajes o ayos de lạs estrellas», porque Dios puede encomendar a la naturaleza que haga por sí misma dicho trabajo: «Mayores obras y no menos

39 Obras Filosóficas del P. Juan Nieremberg, de la Compañía de Jesús, Éthicas, Políticas y Phísicas. Tomo tercero de sus obras en Romance. En Madrid, por Domingo García Morrás, Año MDCLI. El libro sexto, «De la vida de las estrellas y naturaleza de los cielos», consta de 35 pequeños capítulos, de los cuales destacamos los siguientes: 1) Si los cielos y estrellas tiene alma racional; 3) Si tienen los cielos ángeles que los muevan; 5) No hay muchos cielos divididos y sólidos; 9) Si los planetas son más de siete; 13) Los cielos son corruptibles; 4) El cielo no es sólido; 15) Tres cielos solamente hay; 17) No se mueven los planetas al rededor de la Tierra; 18) Al rededor del Sol, Júpiter y Saturno se mueven otros planetas fuera de los siete; 19) Las estrellas no se mueven circularmente; 24) $\mathrm{Si}$ las estrellas tienen alguna vida; 27) Si las estrellas han de morir o renovarse; 35) Cómo aparecen los cometas. 
ordenadas, no menos ingeniosas, ha cometido y fiado Dios a la naturaleza. Los prados matizan las flores, distinguen los colores; los árboles tornean sus ramas, asean las hojas, redondean sus frutos, y no es menester Ángel que les lleve la mano».

\section{OTROS HECHOS POSTERIORES}

Hemos mostrado cómo Mimbela está situado entre la tradición y la modernidad, o si se quiere en la tradición pero asomándose a la modernidad, y esto en la temprana fecha de 1693. Desde este año hasta la fausta fecha de 1760 , en que Mutis desembarca en Cartagena de Indias, hay un largo trecho histórico de sesenta y siete años, en el que las ideas modernas continuaron penetrando en el Nuevo Reino. Hay pruebas fehacientes de que en estos lares la astronomía no estaba tan atrasada en las primeras décadas del siglo XVIII, como puede verse en la magnífica obra de Jorge Arias de Greiff titulada La astronomía en Colombia.

Arias de Greiff destaca, con toda razón y justicia, la figura de Juan de Herrera y Sotomayor. Sabemos de este personaje que ingresó en la milicia en 1667 , que porteriormente viajó a Buenos Aires, donde su padre era gobernador, que allí vivió durante siete años obteniendo el grado de capitán y que posteriormente viajó España. Pero lo importante para nuestra historia es que hacia 1699 aparece don Juan de Herrera en Cartagena de Indias y que allí se radicó hasta su muerte ocurrida el 25 de febrero de 1735. Durante estos años desempeñó, con rango de Coronel, los cargos de ingeniero jefe de las fortificaciones de dicha plaza y gobernador del castillo de San Felipe de Barajas.

Desde el punto de vista científico, el suceso más importante en la vida de don Juan fue la llegada a Cartagena del sabio francés, el abate Feuillée, con quien entabló amistad y en cuya compañía se adentró en los secretos de la Tierra y del cielo. De regreso a Europa, el sabio francés dejó en manos del discípulo cartagenero los instrumentos de observación, entre ellos el anillo astronómico. Con este equipaje pudo observar desde la Ciudad Heroica numerosos eclipses de Luna y varias inmersiones y emersiones de los satélites de Júpiter descubiertos por Galileo; además determinó con exactitud la latitud de Cartagena, Panamá y Santa Marta e hizo llegar estas y otras observaciones a Cassini, del observatorio de París, y a Edmundo Halley, astrónomo Real en Greenvich, en un manuscrito que reposa en la Biblioteca de la Royal Society de Londres. Arias de Greiff como apéndice de su magnífica obra ha editado facsimilarmente el manuscrito de Herrera cuyo título es: Observations astronomiques faites à la Ville de Cartagene des Indes par le Coronel Dn. Juan de Herrera et Sotomayor, ingenieur en Chef de la ditte Place et Gouvernateur pour sa Majesté Catholique du Chateau du St. Philippe de Baraxas hors des Murs, por une plus parfait correction de la Geographie. Contiene dicho manuscrito una carta remisoria a Edmund Halley y las tablas con sus minuciosas observaciones. Arias de Greiff valora la brillante hoja de investigador de Juan de Herrera en la siguiente forma:

«Es necesario destacar lo que esto significa: que se practica a conciencia una astronomía basada en la mecánica celeste establecida por Kepler y Newton; los satélites de Júpiter fueron descubiertos por Galileo, no son del antiguo mundo de Ptolomeo y Copérnico; de modo que se trabaja la ciencia,nueva sin preocupación alguna ni interferencia de discursos ideológicos ni polémicas religiosas, con anterioridad a los grandes debates del siglo XVIII; y todo esto se hace cuando ;Oh prodigio, Newton estaba aún entre los vivos! ${ }^{40}$.

Una segunda prueba de cómo las ideas modernas habían penetrado en las aulas universitarias con anterioridad a la llegada de Mutis, es el manuscrito anónimo titulado Physica spe-

40 ARIAS DE GREIFF, Jorge. La astronomía en Colombia. Santafé de Bogotá, Academia Colombiana de Ciencias, 1993, pp. 26-29. 
cialis et curiosa. Corresponde a un curso de física especial dado en las aulas de la facultad de artes de la Universidad Javeriana en 1755. Su autor, anónimo, no es ciertamente un investigador como lo fuera Herrera, sino de un docente como Mimbela que trasmite los conocimientos de su época. Se sabe que entre 1753-1756 era maestro de artes el antioqueño Juan Antonio Ferraro, por lo cual podemos afirmar con probabilidad que el manuscrito es de su autoría. Pues bien, en este texto leído cinco años antes de la llegada del sabio gaditano al Nuevo Reino, se afirma lo siguiente acerca del sistema de Copérnico y Galileo:

«Esta opinión que se juzgaba en un principio blasfema, poco a poco se ha ido admitiendo en las universidades y en las mismas comunidades religiosas, y ha suplantado a las contrarias. Fuera de España, predomina públicamente en todas las partes, aun en Roma, la sede de la religión; y en España tiene también algunos partidarios. Los mismos jesuitas, que antiguamente la atacaban, hoy la defienden públicamente en Italia, Francia y en algunas regiones de Alemania».

En cuanto a valoración de los diversos sistemas cosmológicos, añade lo siguiente:

«El de Ptolomeo y el Pitágoras están en contradicción con las observaciones de los astrónomos. El de Tycho no se ha podido comprobar. El de Copérnico es el más sencillo, pero es considerado poco católico. Por lo cual casi todos los hispanos lo rechazan como tesis, pero algunos lo admiten como hipótesis, porque es tal que explica correctamente todos los movimientos de los planetas, como si fuera un sistema verdadero. Pero parece repugnar a la fe puesto que hay muchos textos de las Escrituras atribuyen quietud a la Tierra y movimiento al Sol y demás astros. A lo cual responden los copernicanos que la Escritura habla así, acomodándose al lenguaje del vulgo que así piensa y habla» ${ }^{41}$.

En conclusión, el Nuevo Reino no estaba tan yermo de conocimientos, ni los neogranadinos tan vírgenes de modernidad cuando en 1760 vino a quedarse entre nosotros José Celestino Mutis; aunque, como siempre pasa, todavía quedaban por estos pagos pequeños reductos de «intransigentes», aferrados a la vieja «imago mundi».

\section{FUENTES Y BIBLIOGRAFÍA}

\section{Manuscritos de Mateo Mimbela}

Physices tractatus P[er] R. P. Matheum Mimbela Societatis Jesu, dignissimum philosophiae Cathedrae praeceptorem huius Xaverianae Accademiae civitatis Sanctafidensis. Die vigesima mensis octobris anno a nativitate Dni. 1693. Joanne de Herrera auditore. 148 folios (21 x 15). El manuscrito se conserva en la Biblioteca Nacional, man. 149. David García Bacca tradujo algunos aparte del mismo referentes a la esencia y existencia de la materia prima y de la forma sustancial, Cf. Antología del pensamiento filosófico en Colombia, pp. 223-232; recientemente Miguel Ángel González Castañón, como trabajo tesis del magister en filosofia latinoamericana de USTA, tradujo y estudió el primer libro, que trata de los principios intrínsecos del ser natural.

Brevis tractatio de caelo et astris. Escrito por el mismo copista y encuadernado en el mismo códice con el anterior, no obstante tiene numeración propia de 1 a 12 folios. En él Mimbela cita cuatro veces (nn. 7, 29, 31, 48) lo que dijo en el Physicae tractatus, lo cual indica que el Tratado del cielo es posterior y complementario. Hay una mala traducción del mismo, publicada en Cuadernos dé filosofía latinoamericana, 43-44 (1990) pp. 121-146. 
Tractatus de essentia et atributis Dei. Per R. P. Matheum Mimbela vespertinae cathedrae moderatorem dignissimum. Initium dedi die 19 mensis octobris. Anno 1699. Consta de 115 folios (21 x 13). Está encuadernado en pergamino en un mismo códice con Tractatus scholasticus et theologicus de divina providentia et praedestinatione Per R. P. Iosephum de Molina, auditore D. Mtro. D. Iosepho Dias Quixano D.B.R. [Divi Bartholomei Realis] et Mayoris, dedit 21 octobris anni Dni. 1737. Dicho códice pertenece a Ia Academia de la Historia. García Bacca tradujo las dos primeras cuestiones referentes a la cognoscibilidad y existencia de Dios, Cf. Antología del pensamiento filosófico en Colombia, pp. 327-352.

Señalaremos, en forma abreviada (BN = Biblioteca Nacional y BJ = Biblioteca Javeriana), el lugar donde se encuentran las obras citadas por Mimbela, así como el número del manuscrito correspondiente a las citas. Para una más amplia referencia de las fuentes, Cf. DEL REY, José. Las mentalidades en el Nuevo Reino: La Universidad Javeriana. Tomo II: La Biblioteca en 1767. Santafé de Bogotá, Pontificia Universidad Javeriana y Universidad Católica del Táchira, 1998.

\section{Fuentes citadas por Mimbela}

AGUSTINUS, S. Opera omnia. 11 vols. Lugduni 1586; 1636, BJ. Parisiis 1613, BN. Cit. nn. 24, 81.

ALAPIDE, Cornelius. Commentaria in quatuor prophetas maiores. Antuerpiae, $1622 \mathrm{BN}$; Antuerpiae 1692, BJ. Cit. n. 42.

ALBERTUS MAGNUS, S. Cit. n. 18.

ALFONSO, Franciscus. Disputationes in duos libros Aristotelis de generatione et corruptione, in quatuor libros de meteoris et in tres libros de caelo. Compluti, 1641. Disputationes in octo libros physicorum Aristotelis. Compluti, 1641 BN. Cit. n. 18.

ALFONSO X (el Sabio), Cit. n. 47.

AQUINATIS, S. Thomas. Summa theologiae S. Thomae Aquinatis. Romae, 1619; Lugduni, 1701 BN; Parisiis, 1663, BJ. Opera Divi Thomae Aquinatis. 22 vols. Parisiis, 1538, Romae, 1570, Antuerpiae, 1612 , BN. Cit. nn. 74, 81.

ARISTARCUS, Cit. n. 60.

ARISTOTELES (Philosophus). Aristotelis de caelo, de generatione et corruptione, metereologicorum, de plantis, cum Averrois Cordubensis varis in eosdem commentariis. Veneciis, 1562, 1612, BN; Aristotelis Metaphysicorum libri XIII, cum Averrois Cordubensis in eosdem commentariis. Veneciis, 1612, BN. Cit. nn. 1, 10, 18, 21, 33.

ARRIAGA, Rudoricus. Cursus philosophicus. Antuerpiae, 1632. Disputationes theologicae. 17 tom. Antuerpiae, 1643, BN. Cit. n. 18.

BIBLIA VULGATA (trad. latina de S. Jerónimo y castellana del P. Felipe Scío, 2 tom.) Valencia 1790, BJ. Para las citas en español nos atenemos a esta traducción española, la mas antigua entre las católicas: Gen. 1,$14 ; 1,17 ; 15,5 ; 22,17$ y 26 ; Jos. 9,$13 ; 10,12 ; 10,13 ; 10,13$ y $14 ;$ Job 37, 18; 37, 71; Sal. 32; 101; 113; 135; Prov. 3, 19. Ecl. 1, 5; Is. 64, 1; 51, 6; Ez. 1; Act. 4, 14; 17, 26; I Cor. 15, 41; II Cor. 12, 13. I Pe. 3, 11-13; II Pe. 3, 10; Ap. 21, 1.

BRAHE, Tycho. Cit. nn. 34, 59.

BONAVENTURA, S. Cit. n. 18.

CELADA, Didacus. Electa sacra de benedictionibus Patriarcharum. Lugduni, 1641 BN y BJ. Cit. n. 67.

CLAVIUS, Cristophe. «Letres à Galilée», en Opere di Galileo Galilei, Firenze, 1851, t. VIII, pp. 3, 4 y 120. Refer. n. 28.

COLLEGIUM CONIMBRICENSE. Commentarii in quatuor libros de caelo Aristotelis Stagirae. Lugduni, 1608, BN; Commentarii Collegii Conimbricensis Societatis Jusu in octo libros physicorum Aristotelis. Lugduni, 1592, BN; Lugduni, 1602, BJ. Cit. nn. 18, 33, 71.

COMPTONUS (Compton), Thomas. Philosophia universa. Anturpiae, 1664, BJ. Cit. nn. 33, 34, 37.

COPERNICUS, Nicolás. Cit. n. 60.

CRISOSTOMUS, S. Joannes. Opera omnia. 5 vols. Paris, 1613. Cit. n. 42.

DAMASCENUS, S. Joannes, Opera omnia. 2 vols. Parisiis, 1603, 1606. Cit. n. 2.

DE LA TORRE, Bartolomé (1647-1704) era catedrático de teología en la Universidad Javeriana, cuando Mimbela iniciaba su magisterio en filosofía. De sus lecciones se conserva el manuscrito Tractatus theologicus de scientia et voluntate Dei.

DIONISIUS, Aeropagita. Opera. Antuerpiae, 1634. Cit. 19, 20. 
GALILEO GALILEI. Aunque no es citado expresamente, hay abundantes referencias a sus descubrimientos: nn. $3,26,35,54,81$.

GREGORIUS, S. Cit. n. 18.

HURTADO DE MENDOZA, Petrus. Disputationes a Summulis ad Metaphysicam. Vallisoleti, 1615, BJ; Disputationes de universan Philosophia. Lugduni, 1617. Cit. nn. 18, 25, 50.

LESSIUS, Leonardus. Opuscula theologica. Parisiis, 1626, BJ. Cit. n. 67

MOLINA, Ludovicus. Commentaria in primam D. Thomae partem. Lugduni, 1593, BN; Veneciis, 1594 y Lugduni, 1622, BJ. Cit. n. 18.

NIEREMBERG, Joannes Eusebius, Historia naturae. Antuerpiae, 1635, cit. nn. 20, 21, 34; Obras Filosóficas del P. Juan Nieremberg de la Compañía de Jesús, Ethicas, Políticas y Phísicas. Madrid, 1651 y Sevilla, 1686, BN.

ORIGENES, Adamantii. Opera. 4 vols. Lugduni, 1536, BJ. Cit. n. 1.

ORTIZ MORALES, Joseph. Observaciones curiosas y doctrinales..., 1713, BN man. 345.

PITÁGORAS, Cit. n. 60.

MARTÍNEZ DE RIPALDA, Joannes. De usu et abusu doctrinae Divi Thomae. Leodii, 1704. Hay 4 ejemp. en BN; 2 en BJ; y 1 en Convento S. Domingo. Cf. mi obra Los principios de la intelección humana del maestro javeriano Juan Martinez de Ripalda.

RICCIOLI, J. Baptista. Almagestum Novum Astronomiam veterem novamque complectens. 3 vols. Bononie, 1651; Astronomia reformata, Bononiae, 1665. Refer. n. 38.

SCHEINER, Christophe. Tres epistolae de maculis solaribus scriptae ad Marcum Velserum. 1612, reimpresas en Opere di Galileo Galilei. Firenze, 1843, vol III, pp. 272-380. Refer. n. 27.

SPINOLA, Estephanus. Novissima philosophia. Genovae, 1651, BN.

SUÁREZ, Franciscus. Metaphysicarum disputationum. Salamanca, 1597. Hay otras ediciones: Moguntiae, 1605, 1619; Colonia, 1608, 1614; Genovae, 1636, BN. Cit. n. 18.

SUÁREZ (Lucitanus), Franciscus. Cursus philosophicus. 4 vols. Coimbra 1651. Es frecuente confundirlo con el homónimo granadino, el Doctor Eximio; el Luxitano (1605-1659) fue también jesuita y profesor en Coimbra. Cit. nn. 10, 21, 34.

TANNERUS (Tanner), Adamus. Universa theologia schoslastica. 4 vols. Ingolstad, 1626, BJ. Cit. n. 33. TEOFRASTES, Cit. 18.

VIEGAS, Blasius. Commentarii exegetici in Apocalypsim. Eborae, 1601, BJ. Cit. n. 57.

XENOFANES, Cit. n. 6.

ZARAGOZA, P. Joseph. Esphera en común, celeste y terráquea. Madrid, 1675, BN.

\section{Bibliografía}

ABELLÁN, José Luis. Historia crítica del pensamiento español. Vol. II: La edad de Oro (s. XVI). Vol. III: Del Barroco a la llustración (ss. XVII y XVIII). Madrid, Espasa-Calpe, 1979 y 1981.

ABBETTI, G. Historia de la astronomía. México, FCE, 1956.

ANÓNIMO. Nueva física natural. Physica naturalis et curiosa. Manuscrito de 1755. Transcripción de texto latino, traducción e introducción de Pedro Nel Ramírez. Bogotá, Universidad Santo Tomás, 1988.

ARBOLEDA, Luis Carlos. «Acerca del problema de la difusión científica en la periferia: el caso de la física newtoniana en la Nueva Granada (1740-1820)», en Ideas y Valores 79 (1989) pp. 3-26; «Matemáticas, cultura y sociedad en Colombia», en Historia social de la ciencia en Colombia. Tomo II: Matemáticas, Astronomia, y Geología. Bogotá, Colciencias, 1993, pp. 15-172; «Mutis entre las matemáticas y la historia natural», en Historia social de la ciencia en Colombia: sabios, médicos y boticarios. Bogotá, Colciencias, 1986, pp. 11-24.

ARIAS DE GREIFF, J. Historia de la astronomía en Colombia. Bogotá, Academia Colombiana de Ciencias, 1993.

CASSANI, Joseph. Historia de la Provincia de la Compañía de Jesús del Nuevo Reino de Granada en la América. Madrid, 1741, BN.

COTARELO VALLADOR, A. «El P. José Zaragoza y la astronomía de su tiempo», en Estudios sobre la ciencia española del siglo XVII. Madrid, 1935.

CEÑAL, Ramón. «La filosofía española del siglo XVII», en Revista de la Universidad de Madrid, 42-43 (1963). 
DEL REY FAJARDO, José. Las mentalidades en el Nuevo Reino. La Universidad Javeriana. Tomo II. La Biblioteca en 1767. Santafé de Bogotá, Universidad Católica del Táchira y Universidad Javeriana, 1998; La pedagogía jesuítica en Venezuela, 3 vols. San Cristóbal, Universidad Católica del Táchira 1991; Bio-bibliografía de los Jesuitas en la Venezuela colonial. Caracas, Universidad Andrés Bello, 1974.

FERNÁNDEZ, Clemente. La filosofía escolástica de los siglos XVI y XVII. Madrid, BAC, 1986.

FRAILE, Guillermo. Historia de la filosofía española. 2 vols. Madrid, BAC, 1971-1972.

GARCÍA BACCA, Juan David. Antología del pensamiento filosófico en Colombia de 1647 a 1761 . Bogotá, Imprenta Nacional, 1955.

HERNÁNDEZ DE ALBA, Guillermo. Documentos para la historia de la educación en Colombia. 3 vols. 1968; Pensamiento científico y filosófico de José Celestino Mutis. Bogotá, Banco Cafetero, 1982.

JARAMLLO MEJÍA, William y otros. Real Colegio Mayor y Seminario de San Bartolomé. Colegiales de 1605 a 1820. Santafé de Bogotá, Instituto de Cultura Hispánica, 1996.

LERTORA MENDOZA, Celina. Fuentes para el estudio de las ciencias exactas en Colombia. Santafé de Bogotá, Academia Colombiana de Ciencias, 1995.

LÓPEZ PIÑERO, José María. Ciencia y técnica en la sociedad española de los siglos XVI y XVII. Barcelona, Labor, 1979; La ciencia en la historia hispánica. Mađrid, Salvat, 1986.

MARQUÍNEZ ARGOTE, Germán. Los principios de la intelección humana del maestro javeriano Juan Martínez de Ripalda (1641-1707). Santafé de Bogotá, Pontificia Universidad Javeriana, 1998.

MARQUÍNEZ, G. y BEUCHOT, M. (Edit.). La filosofía en la América Colonial. Santafé de Bogotá, El Búho, 1996.

MARTÍNEZ-CHAVANS, Regino. «La física en Colombia. Su historia y su filosofía», en Historia social de la ciencia en Colombia. Tomo VI: Física y Química. Bogotá, Colciencias, 1993, pp. 17-183.

MERCADO, Pedro. Historia de la Provincia del Nuevo Reino y Quito de la Compañía de Jesús. Bogotá, 1957.

NEGRÍN, O. y SOTO, D. «El debate sobre el sistema de Copérnico en la Nueva Granada durante el siglo XVIII», en Revista Colombiana de Educación 16 (1985).

PACHECO, Juan Manuel. Los Jesuitas en Colombia. 3 vols. Universidad Javeriana, 1959, 1962, 1989; y «La Universidad Javeriana», en DEL REY, La pedagogía jesuítica..., pp. 77-173; Ciencias, filosofía y educación en Colombia en el siglo XVIII. Bogotá, ECOE, 1984.

PINZÓN GARZÓN, Rafael. La filosofía en Colombia. Bibliografía de los siglos XVI, XVII y XVIII. Bogotá, USTA, 1989.

QUECEDO, Francisco. «Manuscritos teológico-filosóficos santafereños», en Ecclesiastica Xaveriana. 2 (1952).

RIVAS SACCONI, José Manuel. El latín en Colombia. Bosquejo histórico del humanismo colombiano. Bogotá, Instituto Caro y Cuervo, 1949; otras edic.: Colcultura, 1977; Planeta, 1998.

RODRÍGUEZ CRUZ, Agueda. Historia de las universidades hispanoamericanas. 2 vols. Bogotá, Instituto Caro y Cuervo, 1973.

SAGASTI, Francisco. «Esbozo histórico de la ciencia en América Latina», en Ciencia y tecnología en Colombia. Bogotá, Colcultura, 1978.

SALAZAR, José Abel. Los estudios eclesiásticos superiores en el Nuevo Reino de Granada (1563-1810). Madrid, CSIC, 1946.

SILVA, Renán. Universidad y sociedad en el Nuevo Reino de Granada (siglos XVII y XVIII). Santafé de Bogotá, Banco de la República, 1992.

SOMMERVOGEL, C. Bibliothéque de la Compagnie de Jésus. 11 vols. Brusseles-Paris, 1890-1932.

SOTO ARANGO, Diana. Polémicas universitarias en Santafé de Bogotá, siglo XVIII. Santafé de Bogotá, UPN y Colciencias, 1993; La Ilustración en las Universidades y Colegios Mayores de Santafé, Quito y Caracas. Estudios bibliográfico y de fuentes. Santafé de Bogotá, UPN y Colciencias, 1994.

VERGARA Y VERGARA, José María. Historia de la literatura en la Nueva Granada. 2 vols. Bogotá, Banco Popular, 1974. (1ª edic. de 1867).

Germán Marquínez Argote

Diego Ros y Medrano, $2,4^{\circ} \mathrm{D}$. izda.

28806 Alcalá de Henares

gmarquineza@hotmail.com 